Studies in African Lingustics

Volume 22, Number 3, 1991

\title{
THE CONSONANT INVENTORY \\ OF PROTO-EASTERN CUSHITIC
}

\author{
Christopher Ehret \\ UCLA
}

\begin{abstract}
Previous work on the Eastern branch of Cushitic, most notably the work of Hans-Jürgen Sasse, established a solid initial reconstruction of the protoEastern Cushitic (PEC) consonants. This initial system had about 20 to 23 consonants. Further work by Linda Arvanites indicated the existence of several additional consonants. The current work rounds out the PEC consonant system and shows it to consist of 30 consonants in all. These form a moderately well-balanced system of voiced stops, voiced implosives in four different positions of articulation, and voiceless stops and ejective stops in three different positions of articuation. PEC also had five non-laryngeal fricatives, the full array of laryngeals that one has come to expect from Afroasiatic languages, $1, \mathrm{r}, \mathrm{w}, \mathrm{y}$, and most interestingly, four different nasals, including $n$ and $\eta$, this latter distinction not widely recognized as a feature of Afroasiatic. A side effect of this reconstruction is a first provisional history of the reflexes in Eastern Cushitic languages of PEC geminates. Along with this history, an explanation is proposed for the derivation of the Yaaku 7-vowel system from the PEC system of 5 vowels, long and short.
\end{abstract}

\section{Expanding the PEC Consonant System}

Hans-Jürgen Sasse's [1979] ground-breaking work on the consonant reconstruction of proto-Eastern Cushitic (PEC) solidly established the existence of at least twenty-one PEC consonants. But it soon became apparent, once a substantial reconstruction of proto-Cushitic (PC) had been developed [Ehret 1987], that a number of additional PEC consonants had to be posited. Further, it was clear by implication from the PC reconstruction, if not always explicitly stated, what kinds of articulatory positions inose consonants most probably occupied. 
Sasse's subtitle of his article, "A first approximation", reflected his own awareness that there was much more to be learned about the PEC consonants. His inventory comprised three regular voiced stops, ${ }^{*} b,{ }^{*} d$, and ${ }^{*} g$; their voiceless counterparts in two positions, ${ }^{*} t$ and ${ }^{*} k$; two glottalic stops opposite in voicing, ${ }^{*} d^{\prime}$ and ${ }^{*} k^{\prime}$, along with a third glottalic he renders as ${ }^{*} d_{1}$, and which at one point he suggests might itself conflate two separate consonants; the fricatives ${ }^{*} s, *^{*}, *_{z}$, and possible ${ }^{*} x$; four laryngeals ${ }^{*}$ ?, ${ }^{*} \uparrow,{ }^{*} \hbar$, and ${ }^{*} h$; the nasals ${ }^{*} m$ and ${ }^{*} n$; the liquids ${ }^{*} r$ and $* l$; and also ${ }^{*} w$ and $* y$. The very unbalanced distribution of articulatory positionings in this system, graphically visible in tabular form below, is enough by itself to indicate that more PEC consonants remained to be discovered.

\begin{tabular}{llll}
$b$ & & $g$ & \multicolumn{1}{c}{} \\
$t$ & & $k$ & $?$ \\
$s$ & $s$ & $(x ?)$ & $\hbar, h$ \\
$z$ & & & \\
$d^{\prime}, d^{\prime}{ }_{1}$ & & $k^{\prime}$
\end{tabular}

$\begin{array}{ll}m & n \\ & l, r\end{array}$

w

$y$

The process of filling in the gaps in the proto-Eastern Cushitic inventory began in the recent doctoral dissertation of Linda Arvanites [1991]. She shows that Sasse's ${ }^{*} d_{1}$, as he suspected, does indeed conflate two separate glottalic consonants, PEC ${ }^{*} t^{\prime}$ and ${ }^{*} c^{\prime}$, and that an additional voiced glottalic, PEC ${ }^{*} b^{\prime}$, fits the labial slot in the system in tandem with the already well established voiced PEC ${ }^{*} d^{\prime}$ in the dental-alveolar position. She also adds to the evidence for the PEC fricative $* x$.

The present article rounds out the contribution of Arvanites' work with an extensive demonstration of three additional PEC consonants and a necessarily less extended presentation of evidence for two relatively rare consonants. The data adduced below show that the glottalic sets of proto-Eastern Cushitic have two further voiced members, ${ }^{*}{ }^{\prime}$ and ${ }^{*} g$ ', not recognized in Sasse [1979] or argued for explicitly in Arvanites (although implied in Ehret [1987]). They also demonstrate the existence of a further, quite common PEC obstruent ${ }^{*} c$ (marked as ${ }^{*} S$ in Ehret [1987: 140-142]), obscured in the evidence previously investigated for the PEC sibilants. The establishment of these phonemes requires presentation of new evidence on the recognized PEC consonants $*_{s}$ and $*^{*}$ as well as specific substantiation of ${ }^{*}{ }^{\prime},{ }^{*} g^{\prime}$, and ${ }^{*} c$. Two added nasals, ${ }^{*} \eta$ and ${ }^{*} n$, that are not at all common round out the PEC inventory. In addition, new materials are presented for PEC *x, establishing its pattern of sound correspondence in the major Eastern Cushitic languages. Finally, new findings are offered on the history of PEC 
geminate consonants and on the derivation of Yaaku's seven-vowel system from the five vowels of PEC.

The analysis has been helped along greatly by publication in the 1980's of important collections of Soomaali, Afar, and Sidamo data [Ehret and Ali 1983, Ali 1985, Agostini et al. 1985, Parker and Hayward 1985, and Gasparini 1983, along with Keenadiid 1976] that were not available to Sasse in the 1970's. Unpublished Yaaku data collected by the writer [Ehret 1967] have also been used.

The findings here have, as well, important consequences for subgrouping within Eastern Cushitic. The existence of a distinct Lowland East Cushitic branch (identified in Black [1974] and separately postulated in Ehret [1976]) can now be affirmed from shared patterns of phonological innovation found in its constituent members, the Soomaali, West Omo-Tana (Arbore and Dasenech), Oromoid, and Afar subgroups (Ehret [1987] and data on PEC * $g^{\prime}$ and ${ }^{*}{ }^{\prime}$ below). The previously proposed South Lowland division of Lowland East Cushitic, excluding Afar and Saho which can be placed in a separate North Lowland division [Ali 1985], finds solid support in the sound change histories of PEC $*^{*}$ and ${ }^{*} x$ (see $\S \S 1.1 .2$ and 1.4 below).

In the discourse that follows, the particular attestations of a root are presented generally in morphologically analyzed form, with the stem separated from nominal suffixes or verb extensions by hyphens and the suffixation described in parenthesis after the entry. Number-gender markers in nouns and adjectives, usually of the shape $-\mathrm{V}$ but sometimes $-\mathrm{VCV}$, are similarly marked off, but without further comment on their meanings. Syllabic nasals are represented by $\bar{n}$ and $\bar{\eta}$, the voiced and voiceless palatal affricates by $j$ and $c$ respectively, and the implosive labial, palatal, and velar stops by $b^{\prime}, j^{\prime}$, and $g^{\prime}$. The symbol $d^{\prime}$ marks a consonant that manifests itself as the equivalent alveolar implosive in PEC and in most modern-day Eastern Cushitic languages, but produces a retroflex alveolar stop in some of the more northerly tongues, such as Afar and many Soomaali dialects. The utilization of the apostrophe ['] to record the glottal stop is another widespread, although not universal, practice in the representation of Eastern Cushitic data. Two languages have unusual orthographic conventions: in Soomaali $x$ is used for $/ \hbar /, c$ for $/ \zeta /$, and $d h$ for $/ d^{\prime} /$; in Afar, $x$ instead marks $/ d^{\prime} /$, while $c$ denotes $/ \hbar /$ and $q$ marks $/ \mathscr{S} /$. The digraph $s h$ expresses $/ \& /$ in Soomaali and Sidamo data, while $q$ marks actual $/ k^{\prime} /$ in both the Oromo and Sidamo materials. The $q$ of Dullay and Yaaku properly represents a uvular, but an unusual one, an implosive voiceless stop. In Yaaku the voiced stops $b, d, j$, and $g$ are all strongly implosive, though not specifically marked as such.

Throughout, the notation "Soomaali" used by itself before a word refers to the accepted standard Soomaali language, either in its northern [Keenadiid 1976] or southern [Agostini et al. 1985] versions.

1.1. PEC $*_{s}, *_{\check{s}}$, and $*^{*}$. Sasse $[1975,1976,1979]$ identifies two voiceless sibilant correspondence series, one manifested in Oromo as /f/ and in all the rest 
of Eastern Cushitic as $/ s /$ and deriving from PEC $*_{s}$, and the second appearing in both Soomaali and Oromo as $\mid s /$, but as $|s|$ in several other Eastern Cushitic tongues, and attributed to EC * $s$. This accounting leaves out the many examples of Soomaali $/ \$ /$ that cannot satisfactorily be explained as regular palatalizations of PEC $* k$ in front-vowel environments, and it equally neglects the common Yaaku back palatal sibilant $/ s /$. The one example so far noted [Sasse 1979:12] of the numerous Soomaali words in which $/ 5 /$ (orthographic "sh") precedes a rounded back vowel, shub 'to pour,' has been attributed implausibly to an irregular palatalization of ${ }^{*} k$ before $/ u$ / (see root $\# 78$ below for a more satisfactory derivation).

But when Soomaali and Yaaku words that contain $/ s /$ and $/ \$ /$ are compared across the board with cognate forms in other Eastern Cushitic languages, three distinct correspondence patterns in fact emerge. A third sibilant $*_{c}$, already tentatively recognized at the proto-Dullay level by Hayward [1982], can be postulated as the etymon of the added series. It seems most likely to have been articulated as an affricate in PEC, as it is when geminated in Oromo and in certain positions in Saamakko of Dullay. Its occurrences have previously been confused most often with those of PEC * $\xi$, and less often with those of $* s$, when noted at all. A fourth set of correspondences, for the well-established voiced sibilant $\mathrm{PEC} *_{z}$, need to been seen in parallel with those for the voiceless sibilants. The reason is that in some languages this consonant has devoiced to $/ s /$, a potential source of confusion which must be factored out in reckoning cognation:

PEC Afar Soomaali Arbore Oromo Konso Dullay Yaaku Sidamo Burji

\begin{tabular}{|c|c|c|c|c|c|c|c|c|}
\hline$*_{S}$ & $s$ & $s$ & $s$ & $\begin{array}{c}\mathrm{f} \\
s / z /\end{array}$ & $\begin{array}{c}s \\
+ \text { labial] })\end{array}$ & $\boldsymbol{s}$ & $s$ & $s$ \\
\hline$*^{\prime} s^{\prime}$ & $s$ & $\begin{array}{l}s \\
\left(y / i_{-}\right)\end{array}$ & $s$ & $s$ & $\begin{array}{l}s \\
\left(\xi / i_{-}\right)\end{array}$ & $\xi$ & $\zeta$ & $\begin{array}{l}s \\
(\zeta / o)\end{array}$ \\
\hline${ }^{*} c$ & $s$ & $\xi$ & $s$ & $\begin{array}{l}s \\
(c c)\end{array}$ & $\xi$ & $\Im, c$ & $s$ & $\xi$ \\
\hline$*_{z}$ & $d$ & $d$ & $z$ & $d$ & $t$ & $\begin{array}{l}s, z \\
\left(\mathrm{PD} *_{z}\right)\end{array}$ & $s$ & $d$ \\
\hline
\end{tabular}

PEC ${ }^{*} c$ yielded proto-Soomaali ${ }^{*} c$, which Rendille apparently retained as $/ c /$ at least non-initially, and which elsewhere in the Soomaali group shifted to $/ \zeta /$. Geminant ${ }^{*} c c$ produced $/ c c /$ in Oromo. The notation PD identifies the protoDullay etymon. In the Dullay group the reflex /c/ for PEC ${ }^{*} c$ occurs only in Saamakko and even there possibly only in cases of an underlying geminate; other Dullay dialects have $/ \zeta /$ in all cases. Similarly, PD $*_{z}$ is retained as $/ z /$ only in Saamakko, while in the rest of the dialect group it has fallen together with $/ s$ / 
[Hayward 1982]. Hadiya outcomes for each of these consonants are identical with those of Sidamo except apparently that all PEC $* \xi$, including those in environment of $* o$, become $/ s /$.

1.1.1. Proto-Eastern Cushitic *s. The first of the three correspondence series fits exactly with Sasse's set for PEC *s and strongly reconfirms his discovery. Numerous examples can be cited, some of them already well known in the literature of Eastern Cushitic reconstruction (HEC = Highland East Cushitic, LEC = Lowland East Cushitic):

1. *sab- 'to deny'

HEC: Hadiya $s a b b$ - 'to refuse; not be possible; hate';

LEC: Soomaali sassab- 'to deceive; to entice'; Arbore sassab- 'to deceive'; Oromo sob-a 'lie,' sossob- 'to deceive';

Yaaku sap-ar-e 'lie' (stem plus Cushitic nominal suffix in *r)

The LEC languages share in a particular innovated form by reduplication. For other cases of PEC $* a>o / \# s_{-}\left[+\right.$labial] and / $\# b_{-} s$ in Oromo, see roots \#4 and \#42 below. Burji sob-, sosob- 'to deceive' is a probable loan from Oromo because it shows the Oromo vowel-rounding shift. Sasse $[1979,1982]$ connects up Harso sapsap-icce, Gollango saapsap-itte, etc., 'spider' with this root; similar forms appear in Burji naming the spider, and in Arbore denoting a kind of spider.

2. *sag-/*sig- 'far'

LEC: Dasenach seg- 'far'; Oromo fag-oo 'far'; Konso, Gidole sek- 'far';

Yaaku -sek-E' 'far' (Heine [1975] has scke')

The proto-Cushitic (PC) reconstruction of this root is *sag-/*sig-. It was reconstructed as *sog-/*seg- in Ehret [1987:59] because of the writer's mistaken acceptance there of the presumed cognation of the Eastern Cushitic forms in $|f|$. The Southern Cushitic and Yaaku vowels are determinative in this matter. Rift Southern Cushitic *sag- [Ehret 1979] requires the PC vowel *a; Yaaku /e/ derives from PEC, and therefore PC, $* i$ (see discussion of Yaaku vowel outcomes in $\$ 2$ below), whereas the vowel $/ a$ / in the Beja reflex could be from PC ${ }^{*} a{ }^{*} e$, or ${ }^{*} o$ [Ehret 1987]. Soomaali fog-, Arbore fek'-, etc. for 'far' can be attributed to a distinct Cushitic root ${ }^{*} f e g-/{ }^{*} f o g-$ 'to separate, be put apart, be removed', e.g. Southern Cushitic ${ }^{*} \mathrm{feg}$-, as in Iraqw feguus- 'to clear away (vegetation from a field)' (stem plus Cushitic causative), also seen in Semitic * $p g(g)$, e.g. Arabic fajj 'to open the legs, widen a bow' [Ehret 1989:130]. They need not be explained as some kind of irregular extension to other Eastern Cushitic languages of the shift of PEC *s to $|f|$, which is regular only in Oromo. The Oromo word, of course, may also derive from ${ }^{*} f e g-/ * f o g$-. The probable explanation, in this case, of the unexpected $/ e /$ in the Dasenech and Konso-group reflexes is that both ${ }^{*} f e g$ - and 
*sag- existed in early South Lowland East Cushitic (these languages all belong to that subgroup), and that the pronunciation of the one root influenced that of the other.

3. *sa(a)g- 'meat animal'

LEC: Afar sag- $a$ 'cow';

Dullay: Gollango saak-an-ko 'meat' (stem plus Cushitic n. suff. in *n)

The vowel-length difference is as yet unexplained.

4. *samay- '(spear)shaft'

LEC: Soomaali samay-o 'spearshaft; long straight stick'; Oromo som-aa 'spearshaft';

Dullay: Harso samay-ho 'spearshaft'

This entry revises the reconstruction of the root in Sasse [1975, 1982]. Burji somay is apparently a loan from Oromo for the reason cited under root \#1 above.

5. *san-/*sin- 'branch'

HEC: Sidamo sin- $a$ 'branch';

Dullay: Harso, Dobase san-ce, Gollango san-te 'branch'

This root appears also in the proto-Southern Cushitic form *san- 'root, tap root, lower trunk' [Ehret 1979]. Sasse [1976:140] sees the Dullay forms cited here as reflexes of PEC *zaam- 'branch.' But their consistent failure to show the expected vowel length and their maintenance of $/ n /$ in the plural where following ${ }^{*} t$ is lacking [Amborn et al. 1980], in contrast to the presence of vowel length and of $/ \mathrm{m} /$ in the one undoubted Dullay reflex, Saamakko zaamm-e, argues against his solution.

6. *sar- 'to burn (intr.)'

HEC: Hadiya sar-, ser- 'to cook, bake'; Burji saar- 'to boil (intr.)'

Yaaku sar- 'to burn (intr.)'

For lengthening of PEC * $a$ in Burji in some environments of $/ s /$, see roots \#187 and \#193 below.

7. *say- 'to go down'

8. *says- 'to set down' (adds causative to simple stem)

LEC: Afar say- 'to decline, set (of sun)'; Soomaali sees 'base, fondimento';

Dullay: Harso says- 'hinlegen' 
9. *sikk- 'to pierce'

HEC: Sidamo sikk- 'to penetrate (a splinter into skin)';

LEC: Afar siik-in-tu 'splinter' (stem plus Cushitic n. suff. in *n, plus form of EC *t singulative suff.);

Dullay: Gollango siik-o, Dobase sik-o 'Beilklinge (mit Absatz)'

10. *sil- 'to rest'

HEC: Sidamo sil-i'-m-a 'nap, snooze, doze' (middle voice stem, *sil-id'-, plus Cushitic n. suff. in *m);

LEC: Afar silaal- 'to rest at noontime in the shade' (partially reduplicated stem by the CVCaaC- vocalization seen also in examples in \#15 and \#119, the determinants and significance of which remain to be worked out);

Yaaku -sel- 'to rest'

Oromo sillimii 'short nap' is an evident loan from an HEC language.

11. * siil- 'vagina'

HEC: Sidamo sill-a 'uterus, womb';

LEC: $\quad$ Soomaali siil 'vagina (of woman)';

Dullay: Harso, Gollango siil-akko 'clitoris'

12. * siill- 'thin fluid'

LEC: Arbore sill-a 'first milk'; Oromo fill-ee 'light rain'

13. *sizzeh-/*sazzeh-/*sazzoh- 'three'

HEC: Sidamo sase, Hadiya saso 'three';

LEC: Afar sadoc 'three'; Soomaali siddeh 'three'; Oromo saddee 'three'; Gidole setti 'three'

Dullay: Harso ezzah, Dobase sizeh, Gollango izzeh 'three'; Saamakko zeeh 'three'

The northern HEC languages in this instance all evidence an early assimilation shift, $*_{z}>*_{s} / \# s V_{-}$V\#, dating before $*_{z}>d$ in Sidamo and Hadiya, which appears even in those languages such as Kambatta (whose forms have not been cited here) where $\mathrm{PEC} *_{z}>z$. Konso sessa 'three' for expected *setta belongs, in contrast, to a wider set of words demonstrably borrowed, by reason of their showing Dullay sound correspondences, e.g. /s/ for PEC $*_{z}$ ), from a dialect of the Dullay, whose territories intertwine with those of the Konsoid group [Black 1974; Sasse 1976].

\section{4. *sizzent-/*sazzent- 'eight'}

HEC: Sidamo sett-e 'eight'; Hadiya sadent-o 'eight';

LEC: Soomaali siddeed 'eight'; Oromo saddeet 'eight'; 
Yaaku siit-e 'eight';

Dullay: Harso, Dobase sass-e, Gollango sett-e, Gawwada satt-e 'eight'; Saamakko sezzen 'eight'

This reconstruction differs from previous postulations in trying to account for the $/ n /$ of the Hadiya and Saamakko forms of the root. Burji hiditta and Kambata hezzetto 'eight' are not in some skewed way related to the root of \#14. They can be seen to be built on the Omotic root for 'three' (Ometo languages, in particular, have hedz-, hezz-, etc., for 'three'), reckoning the numeral eight on a base-five system, and thus must be loanwords from an Omotic language. The regular Eastern Cushitic root for 'eight' depicted here is, of course, also an apparent base-five formation from the PEC root for 'three', preceding in \#13.

Roots \#13, \#14, and also \#145 below illustrate the blocking of Oromo's *s > /f/ shift in the environment of a following PEC sibilant $*_{z}$ (Sasse [1979] identified this effect). A variety of irregular assimilations and coalescences have affected the sequence of $*_{s}$ and $*_{z}$ in Eastern Cushitic languages, most notably in HEC, Dullay, and Yaaku.

15. *sunn- 'to pull out'

LEC: Arbore suun- 'to pick'; Oromo funaan- 'to gather, pick up in field' (CVCaaCvocalization pattern; see also \#10 above);

Yaaku -sun- $t$ - 'to stretch (as hide in tanning)' (stem plus Cushitic ${ }^{*} t$ continuant extension, removing boundedness of action implied in simple root, i.e. 'pull out' > 'pull, keep pulling'); -sun-t-is- 'to straighten' (1st entry plus *s caus.)

16. *suu?- 'to call out'

HEC: Sidamo $s u^{\prime}-m-a$ 'name'; $s u^{\prime}-m$ - 'to call by name' (stem plus Cushitic n. suff. in ${ }^{*} m$; verb is back-formation from noun); Hadiya summ- $a$ 'name';

Yaaku -soo'- 'to cry'

PEC *? instead of $* S$ is required by the Yaaku shift of PEC *uu to /oo/ (for Yaaku vowel shifts see $\$ 2$ below). Despite its surface resemblance to the wide Afroasiatic root *sim-/*sum- 'name,' the general North HEC root for 'name' cited here in its Sidamo and Hadiya forms must derive, because of its medial glottal stop, from this distinct verb root, by addition of the old Cushitic and Afroasiatic $* m$ deverbative suffix.

17. *mas-/*mis- 'cord'

LEC: Soomaali mas 'snake'; Dasenech mas 'Seil';

Yaaku mis- $a$ 'thong'

This entry corrects Sasse's [1976] postulation of *maš-. It should not be confused with the distinct root *mof-/*bof-denoting some kind of snake. 
18. * ?uss- 'stomach contents'

HEC: Burji us-i 'intestines';

LEC: Soomaali uus 'stomach contents';

Dullay: Harso, Dobase, Gollango us-ko 'Panseninhalt'

Further PEC roots containing *s can be found at \#145, \#193, \#216, and \#217 below among the evidence illustrating PEC * $g$ ' and $* x$.

A variety of additional solid cases of PEC ${ }^{*} s$ have been published by Sasse and others, among them *sabeen-/*sibeen-/*subeen- 'ewe-lamb'; *saal- 'dung'; *sag'to talk'; *sanun-/*sunun- 'to have nose bleed'; *sar-/*ser-/*sir-/*sur- 'relative'; *sa?-/ *si?- 'Acacia sp.'; *sa?n- 'sole'; *sid- 'to carry'; *sinc'- 'urine' (for the PEC *c' in which, see Ehret [1987]); *so?- 'meat'; *suun-/*sunn- 'strap, thong' (Sasse [1979] has *suun-, but the Sidamo reflex sunco, pl. sunna requires the latter alternate); *surk-/ *sukr- 'to push'; *surn- 'nasal mucus'; *sus- 'to attach, tie'; *bis- 'color'; *gasaar- 'buffalo'; *gaas- 'horn'; *gaws- 'molar teeth' or 'jaw'; *hinaas - 'to be jealous'; *j'uus - 'to fart' (*d'uus - in Sasse [1975] and [1979]—see root \#167 below); *-kils-/*-kuls-/*-klis-/*-klus- 'to be fat'; *kurs'round, humped'; *k'osl- 'to laugh'; *mo(o)s- 'old'; *nafs-/ *nefs- 'to breathe' (> *nass-/*ness-); *2is-/*?us- 'self'; *wisl- 'to dream'; *?us- 'he'; and *Yusl-/ *Yisl'heavy.' To this last root should be added Yaaku $\varepsilon s i n$ and Jiiddu Pasl-e, which reflect a third stem shape ${ }^{*}$ Casl-.

One root containing PEC *s, the pronoun * Ris- 'she,' is reconstructed in Sasse [1979] as * Pis-, but its shapes in Yaaku, isi, and Dullay, ise, both require original ${ }^{*} s$. Sasse was led to his reconstruction by the South Lowland East Cushitic (SLEC) forms of this root, which do reflect earlier * $s$. PEC $*_{s}$ widely became $|s|$ in SLEC languages - by what were probably synchronic preservations of a protoSouth Lowland morphophonemic shift-in the restricted stem-final environment /-i_-\# (see also Konso outcome in sibilant correspondence table above). The same sound change accounts for the SLEC form of the Eastern Cushitic causative allomorph, *-is-, which became $*_{-} i s_{-}$in proto-South Lowland (see Hayward [1984]), and therefore can be seen as one of the indicators of the validity of South Lowland as a genetic subgroup of Eastern Cushitic.

A lexical example in Soomaali evinces the effects, too, of this SLEC phonological innovation: Sasse [1976] proposes a PEC root *has- 'to hold, keep', but its reflexes in the various Soomaali dialects and languages and in Afar-Saho require a reconstructed root pair:

19. *hay- 'to put, set in place'; *hays- 'to take, receive'

LEC: Afar hay- (hee) 'to put, place'; hays-it- 'to place (etc.) f.o.b.'; haysit 'claimant'; Soomaali hay, Maay haay, Jiiddu hees 'to hold';

Dullay: Harso, Dobase, Gollango hayy- 'befehlen' 
Afar attests both the simple and extended shapes. The Soomaali reflexes all derive from the second form, in a proto-Soomaali (PS) shape *hays-, from earlier *hay-s-, with the usual PS and LEC * $[\xi]<$ PEC *s $/ i \sim y_{-}$.

\subsubsection{Proto-Eastern Cushitic $* \check{s}$. The second correspondence set,} reconfirming PEC $* \xi$, differs from Sasse's principally in having Yaaku $/ \zeta /$ (and never $/ s /$ ) as its outcome in that language. Its reflex throughout the Soomaali group, including Jiiddu, is $/ s /$, except apparently in limited non-initial environments (in particular, $/ i_{-}-\#$ discussed just above). Its normal outcome in Sidamo and Hadiya of the Northern branch of Highland East Cushitic is $/ s /$, although in environment of $/ o /$ it remained $/ s /(s h)$ in Sidamo (see \#32, \#35, \#37, and $\# 44$ below). In the single South HEC language Burji, its regular reflex is $/ \$\rangle$. $\mathrm{PEC} * \xi$ is the least common of the three voiceless sibilants.

20. *saak'- 'to open up'

HEC: Sidamo saaq- 'to open wide, throw open'; Burji saak'- in irk'a saak'- 'to smile' (irk'a 'tooth'; i.e., to open the teeth)

LEC: Soomaali saaq 'espandersi su qn. o qs.'; Oromo saaq- 'to open, uncover';

Yaaku -saq- $d$ - 'to spread (intr.)' (stem plus PEC * $d$ ' middle voice extension)

21. *'saan- 'moist'

LEC: Afar saan-iyya 'cold dampness' (stem plus Cushitic n. suff. in *y);

Yaaku saan-o 'dung of large animals'

Burji's suite of words-saan-ee 'soft,' saan-?-, saan-d' 'to become soft, smooth, moist' (stem plus EC middle voice extension), and saan-s- 'to make soft, smooth, moist' (stem plus Cushitic caus.) - are best counted among the loanwords of the language because of their attestation of $/ s /$ for expected $/ \xi /$.

22. *sang- 'ox'

HEC: Sidamo sang-a 'stallion, bullock'; Hadiya sang-a'a 'Schlactochse';

LEC: Afar sang-a, sank-a 'gelded animal'; Soomaali seng-e 'stallion'; Oromo sang-a 'ox'

Burji sang-a 'ox' shows $/ s /$ for expected $/ \zeta /$ and is therefore, like saa 'cow' in the language, a borrowing, most probably from the Burjis' cattle-keeping neighbors, the Oromo.

23. *sarb- 'shank'

HEC: Sidamo saraw- $a$ 'calf of leg';

LEC: Afar sarb- $a$ 'calf, lower leg'; Arbore sarb-a 'shin'; Oromo sarb-aa 'calf';

Dullay: Harso, Gollango §arp-akko 'vulva, vagina' 
Burji sarb-aa 'calf of leg' does not show regular correspondence here and appears to be a straightforward loan from Oromo.

24. 'sarrk'-/*surrk'- 'to wind, twist'

HEC: Sidamo sarraaq- 'to wind a thread'; Burji צar?um- 'to become wrinkled' (stem plus Cushitic * $m$ intr. extension);

LEC: Soomaali: Garre, Tunni suruq-o 'cow with twisted horns'

25. *saws- 'beehive'

HEC: Burji צaw?-an-aa 'beehive' (stem plus n. or number suff. in *n);

Yaaku కooso' 'beeswax' (reduplicated stem);

Dullay: Harso, Dobase §aaw-ce, Gollango §aaw-te 'beehive'

The reconstruction of the pharyngeal $* S$ here is required by the probable Southern Cushitic cognate seen in proto-Rift (PR) * $c a \xi$ - 'honeycomb' (PSC * $\zeta>$ PR ${ }^{*} c$; in Ehret [1980:362], the available evidence allowed PR ${ }^{*} c^{\prime}$ and ${ }^{*} t s^{\prime}$ as other alternative initial consonants). Its loss in Dullay accounts for the long $a a$ attested there.

26. *sa?- 'to be mistaken'

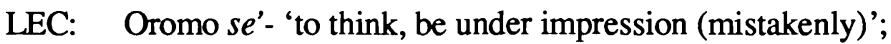

Yaaku $-\Im a^{\prime}-n-a t$ - 'to forget' (stem plus Cushitic n. suff. in ${ }^{*} n$ plus Cushitic $*_{t}$ continuative extension as denominative)

27. *צa?n-/*צi?n- 'skin'

LEC: Soomaali saan 'pelle spessa di animale conciata';

Yaaku $\zeta e^{\prime} n$-o 'bark of tree'

28. * $s a 3 m-/ * 3 i$ im- 'brain'

HEC: Sidamo samm-o, samm-icco 'sinciput; middle of the skull where children still have cartilage'; Hadiya samm-o 'Scheitel';

LEC: Oromo samm-uu 'brain';

Yaaku ‘e'en, pl. so'm-e' 'marrow'

The HEC reflexes require a metathesized root shape * sam?-. Consonant doubling in Oromo is the common outcome of the reconstructible sequences * $\mathrm{YC}$ and $* \Upsilon \mathrm{C}$; e.g. Oromo lap'p'ee 'heart, chest' corresponding to Soomaali laab 'chest' and deriving from PEC *laSb- [Ehret 1987:118]. If the original sequence was opposite in order, either ${ }^{*} \mathrm{C}$ ? or ${ }^{*} \mathrm{C} \uparrow$, then the resultant consonant in Oromo is single, e.g. Oromo sap'ii in root \#32 below. This distinction is not noted in Sasse [1979]. The Yaaku plural form may reflect an underlying shape, *si?um-. 
29. * รeell- 'to convey knowledge'

LEC: Afar seel- 'to be acquainted with';

Yaaku -seel- 'to teach'

A geminant final consonant must be reconstructed to account for the Yaaku vowel (see below for Yaaku vowel outcomes). Burji seer-is- 'to learn' (stem plus causative) is conceivably a regular cognate, providing $/ s /$ is the regular Burji reflex of PEC * $\xi$ /\#_ee. No other cases of this environment are known as yet for Burji, so the possibility remains to be tested.

30. * รem- 'to be good'

LEC: Soomaali san 'stare buono (solo nei composti)';

Yaaku -`En, pl. -seme' 'sweet' (Heine [1975] has $e$ in both the sing. and pl.)

31. * see - 'to be bare, clear'

LEC: Soomaali seen 'annientare qn. or qs.; radere qn.' (*see $m$-, stem plus probably n. suff. in $* m$, with verb derived from earlier noun); seen-yo 'animale privo di corno' (stem seen in preceding item plus Cushitic n. suff. in *y); NW Maay seem-en 'hornless cow' (stem as in preceding entry plus n. suff. in *n);

Yaaku - $\varsigma e e^{\prime}$ - 'to be cloudless (of sky)'; - $\varsigma e e$ '-s- 'to peel' (stem plus Cushitic *s caus.)

The pharyngal $* \uparrow$, rather than $*$, must be reconstructed to account for the Yaaku vowel (see section 2 below).

\section{2. *รob'?-, *รob'Pil- 'pubes'}

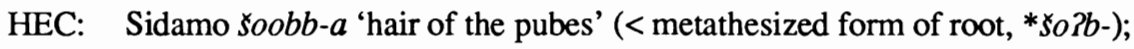

LEC: Soomaali sabiil 'vagina (of animal)'; Arbore sob'-ore 'young male goat' (stem plus Cushitic n. suff. in * $r$; semantics: having genitals, i.e. becoming of an age to reproduce; reference here is to the male equivalent among goats of the heifer among cows); Oromo sap'-ii 'pubic hair';

Dullay: Harso Sob'il-ce 'foreskin'

This root also appears in Southern Cushitic, in Ma'a $i$-รobo 'foreskin'. The simple shape without the suffix in $* l$ may have referred more specifically to 'pubic hair'.

\section{3. * soof- 'to rub with a tool'}

LEC: Soomaali soof 'limare qs.; affilare qs.'; Oromo soof- 'to plane off, hew'

The evidence for this root outside of Eastern Cushitic [Ehret 1987:62] shows it to have begun with $* \xi$ rather than the $*_{s}$ that is also allowed by the available EC data. Sidamo soof- 'to plane, make smooth (wood), scrape, tan (hide), scrub' appears from its lack of usual sh $/ o$ to be a loanword from Oromo. 
34. *sook' $k$ '- 'to smell'

HEC: Burji sook'- 'to stink';

LEC: Soomaali: Jiiddu sok 'nose' ( $\mathrm{PEC} * k^{\prime}>k / s$ in Jiiddu)

The geminated final consonant is indicated by the Jiiddu attestation of sok in place of the shape *suuh to be expected if the root were *sook'-.

35. *รonb- 'lung'

HEC: Sidamo \omb-o 'lung'; Burji צomb-i 'lung';

LEC: Soomaali sanb-ab 'lung' (old pl. form by final-consonant reduplication: lungs occur in pairs); Jiiddu samb-ab 'lung' (derivation as in Soomaali proper); Arbore sonb-ot 'lung' (stem plus * $t$ singulative suff.); Oromo somb-a 'lung'

The Highland East Cushitic evidence shows that this root should reconstruct with initial $* \xi$ rather than $* s$ as sometimes previously posited.

36. * *oor- 'to feed'

LEC: Soomaali soor 'food; to entertain with food and drink'; Oromo soor- 'to feed, nourish'

Sidamo soor- 'to feed' must be reckoned a loan, probably from Oromo, because it fails to retain $|\zeta|$ as it generally does elsewhere in environment $/ o$ (\#32 and \#35 above and \#37 and \#44 below).

37. * soYal- 'four'

HEC: Sidamo sool-e 'four'; Hadiya soor-o, soo'l 'four';

Yaaku ‘wwn 'four' (non-geminate PEC $* l>n /$ VCV_\# in Yaaku; Heine [1975] records కwen);

Dullay: Harso, Dobase, etc. salah- 'four'

The Dullay reflexes show metathesis along with the same process of sibilant assimilation evident among the reflexes of PEC 'nine' (\#105 below), namely, word-initial $* \zeta>/ s /$ in a word normally uttered in sequence with an immediately preceding word beginning in $*_{s}$, in this case for 'three' (\#13 above). PD $* \hbar$ from PEC * /\#CVlV_- is an apparently regular shift (Ehret [1987:117 and 120]). This root also appears in Southern Cushitic as Dahalo sa Sale 'four'; PSC and PC * $\xi>s$ and $*_{o}>a / \# \mathrm{C} \_\mathrm{C} a \mathrm{C}$ - in that language. Note that this evidence requires a revised PEC formulation of the root as * *o Sal- rather than *saSl-, as proposed in Ehret [1987:120]. 
38. *suub- 'belly'

HEC: Sidamo suuw-o 'umbilical cord';

Yaaku soou 'chest'

39. ' $s u k$ '- 'to be knocked apart, pounded up'

HEC: Hadiya suk'k'- schlagen, durch schlagen lockern'; Burji susk'- 'to smash' (regular metathesis of stem plus Cushitic caus.: see Sasse [1982]);

LEC: Soomaali suq-ul 'dust mixed with pulverized dung raised by the wind and deposited in water, food, drink' (stem plus Cushitic n. suff. in ${ }^{*} l$ )

This root is one of four partially resemblant but distinct PEC roots having variously to do with hitting or loosening by hitting: see \#75, \#78, and \#165 below for more on this matter. Soomaali sukul 'pestare qs. per togliere l'embrione (og. granaglie)' and its derived noun sukuliye 'kind of pestle' have shapes explainable by their having originated as loanforms of this root derived from an Afar-related language. The root is not yet recorded from Afar, however.

40. *suuk'- 'narrow (thing)'

LEC: Soomaali suuq-an 'to be(come) long and thin' (stem plus Cushitic * $m$ intr. extension); Oromo suuq-a 'corner, narrow place'; suuq- 'to stick into corner, small place'

41. *suull- 'nail, claw'

HEC: Sidamo suull-ico 'fingernail';

LEC: proto-Soomaali *suul 'nail' (Northern Soomaali 'thumb');

Dullay: Harso susull-e 'claw' (partially reduplicated stem)

42. *bas- 'grassy area'

HEC: Hadiya bass-o'o 'hay'; Burji bas-aa 'grass';

LEC: Oromo bos-on-a 'fertile lowland; grassland' (stem plus Cushitic n. suff. in * $n$; $\mid o /<\mathrm{PEC} * a$ is the shift seen in $\# 1$ and $\# 4$ but in reverse environment);

43. *bis- 'body'

HEC: Sidamo bis-o 'body'

LEC: Afar bis- $a$ 'turtle' (semantics: see comments following); Soomaali: Baraawe biyi 'skin';

Dullay: Harso, Dullay piצ-ko 'body'; Saamakko bis-ko 'body'

The Dullay reflexes of this root have previously been adjudged loan-forms of a distinct PC root, *biz- 'limb of the body' [Ehret 1987:56], but the evidence presented here corrects that attribution. The LEC reflexes share a underlying semantic innovation, a shift in meaning to 'skin,' from which Afar 'turtle' can be derived via the sequence, 'skin' > 'hull, shell' > 'turtle shell.' 
44. *boos- or *b'oos- 'to be spoiled, messed up'

HEC: Sidamo booshaal- 'to be untidy, disorderly' (verb < underlying adj. composed of stem plus Cushitic adj. suff. in * $l$;

LEC: Soomaali boos 'cosa rovinata o logora; persona sfribrata; zoppo'; Oromo boosess- $a$ 'not good-looking, untidy (masc.)' (boos-ett-ii fem.); boos-umm-aa 'untidiness' (stem plus Cushitic n. suff. in *m)

45. *gas- 'abundant hair'

LEC: Soomaali gas 'peli del corpo abondante o lunghi'; Oromo gass-aaw- 'to be bushy (of hair)' (stem plus Cushitic *w inchoative as denominative)

46. *wes- 'to swell; swelling'

HEC: Sidamo wos- $a$ 'abscess on animals';

LEC: Afar os- 'to increase, be more'; os-a 'wart'; Oromo wess-ee 'paralytic disease (swollen belly and face)'

Several other PEC roots previously cited as containing $* \xi$ still appear valid: *saS- 'cow'; *suSs- 'to smell (tr.)'; *\{aws-/* Yays- 'grass'; and *d'is- 'to plant, fix to the ground, build'. The transitive verb * $s u S s$ - 'to smell' is clearly built on an underlying intransitive root * $̌ u$ S- 'to smell,' seen also in the following root, where $*_{-} n$ - is probably the Cushitic noun suffix in ${ }^{*} n$.

47. *su โn- 'odor, bad smell'

HEC: Sidamo su'n- 'to smell, give off an odor' (back-formation from the original noun; compare Sidamo entry in \#16 above for a parallel derivation);

LEC: Soomaali suun 'odore cattivo'

One other root containing PEC $*$, \#218, appears among the evidence for $*_{x}$ taken up below. At least one root previously reconstructed with ${ }^{*} s$, ${ }^{*}$ na?s'breast' [Sasse 1979], known so far only from the Soomaali group of Eastern Cushitic languages (as defined in Ehret and Ali [1983]), may alternatively be posited as *na?s-, since PEC * ${ }^{*}$ usually produces $/ s /$ throughout that group.

Another root, \#48, recorded as yet only from Lowland East Cushitic, has previously been argued to contain medial * $\xi$ [Sasse 1975]. The Soomaali reflex of this root has, however, a particular shape-with a long vowel both preceding and following the medial consonant-that normally implies a reconstructible geminancy of the consonant in question. The outcome of intervocalic PEC *ss in Oromo is not certain (in \#45 and \#46 above, gemination in Oromo is a secondary morphological development). If, as seems possible, it produced single $/ s /$, then this root could attest either $*_{s}$ or * $\xi$. If the Burji reflex is not a loanword, its outcome $/ s /$ would settle the issue in favor of original PEC $* s$. 
48. *haassaw- or *haałsaw- 'to chat, converse'

HEC: Burji haasaaw- 'to chat';

LEC: Afar haasaw- 'to chat, converse (with one participant having to be female)'; Soomaali haasaaw 'to talk, converse, speak'; Oromo haasa(w)- 'to talk, converse'; Konso haasaw- 'schwatzen'

Several further roots, some previously presumed to begin in $\mathrm{PEC} * s$, may on the available evidence contain either PEC $*^{*} s$ or ${ }^{*} s$. In each case attestations in Dullay or Yaaku would help resolve the issue. Two of the roots seem old variants of one original root, differing only in the stem vowel:

49. *sabP- or * $5 a b \uparrow-$ or *sab'P- or * $s a b$ ' - 'soaked matter'

HEC: Sidamo $s a b b-a$ 'mud, soil that has been moistened'; $s a b b$-, sabb-aw- 'to be dirty with mud, turbid'; (stem plus Cushitic *w denominative);

LEC: Afar sabb- $a$ 'seaweed, algae, scum/weeds in stagnant water'; sacab 'seaweed' (metathesized shape of root); sabb-aaw- 'to be washed up on the tide' (stem plus Cushitic *w inchoative); Oromo sap'ap' $p$ '-uu 'slippery growth in river' (partially reduplicated stem)

Northern Soomaali dialect sabbee 'to float' (which adds Cushitic *y denominative verb extension to the root) is a borrowed form of this root, adopted from an extinct Afar-related language, because it shows the expected Afar outcome *sabbrather than the regular Soomaali result *saab- (see also $\S 3$ below).

50. *subP- or *subs- or *sub'?- or *sub'

LEC: Soomaali suub-aan 'pietra levigata, liscia; pianura di sabbia rossa' (stem plus Cushitic n. suff. in *n); Oromo sup'-ee 'clay'

If a third root, for which Dullay reflexes can be proposed, turns out to be still another variant of this stem, with PEC $* i$ as the stem vowel instead of the $*^{*} a$ or $* u$ of \#49 and \#50, PEC $*_{s}$ would be verified as the original initial consonant, and $\mathrm{PEC} * b$ as the medial consonant, of this triplet of roots:

51. *si?b- or *siYb- or *siibb- 'to become wet'

LEC: Arbore siib- 'to anoint, smear';

Dullay: Harso, Dobase siip-, Gollango siipp- 'schwitzen'

But that possibility remains to be adequately established. Harso sip-te 'flacher Korb für Lehm und Fladenbrot' cannot be made to fit phonologically in this set.

Three further roots ambiguous as to whether their first consonants were PEC ${ }^{*} s$ or $* \xi$ can be noted at this point: 
52. *sikk- or *sikk- 'dust'

HEC: Hadiya sikk-o 'dust';

LEC: Soomaali: Garree, Tunni siig-o 'dust'

53. *sik'k'- or *sik'k'- 'large stick'

HEC: Sidamo siqq-o 'stick'; Hadiya siqq-o 'Stock';

LEC: Soomaali siiq-e 'grosso bastone'

54. *si?b- or *si?b- or *si?b'- or *si?b'- 'to extract, draw out'

LEC: Afar siib- 'to unsheathe, uproot'; Soomaali siib 'tirar fuori qs.; estrarre qs.; svellere qs.'; Oromo sip'p'-ad'd'- 'to scoop and eat with the hand' (stem plus EC middle voice extension)

The Soomaali reflex seems quite regular here. If it nevertheless turns out to be a loanword from an Afar-related language, a third reconstruction, ${ }^{*} c i ? b$ - or *ci $\mathrm{i} b$ '-, would become possible for this item.

Another root previously suggested to attest PEC * $\xi$ in fact shows a variety of non-correspondences in every consonant and vowel. Its occurrences include Oromo soodda 'salt' and soogida '(bar) salt,' along with Konso-Gidole sookitta, Arbore sugudda, Dasenech sugutti, Gollango soqo, Harso sookisso, Hadiya sogedo and soqedo, and Burji sogoddi, all meaning 'salt'. Its welter of shapes show it to have spread repeatedly by borrowing. It probably does ultimately derive from an ancient Cushitic root, PC $* d z a x^{w}$-, seen also in Southern Cushitic Kw'adza dzox-ondo 'natron'. In that case its PEC form would have been ${ }^{*} \operatorname{cox}$ - or ${ }^{*}$ cax(see root \#604 in Ehret [1987:140]). But the Wanderwort characteristics of its modern Eastern Cushitic forms would seem to rule out its transmission as an inherited member of PEC vocabulary and instead point to its having reached Eastern Cushitic languages from some other Cushitic source by more recent diffusion.

1.1.3. Proto-Eastern Cushitic ${ }^{*} c$. The third sibilant correspondence set is surely attributable to an originally palatal PEC consonant. We are left with PEC ${ }^{*} c$ as its representation not only because PEC ${ }^{*} s$ is already accounted for, but because Hayward, using Saamakko data, shows it to have been originally ${ }^{*} c$ in certain environments in Dullay. In most Dullay dialects its reflexes have fallen together wholly with those of PEC $* \xi$, hence its appearance usually as $\mid \zeta /$ in the Dullay citations that follow. In proto-Soomaali it remained at first apparently ${ }^{*} c$, still its outcome in the Rendille language of the Soomaali subgroup. The number of $/ c /$ in the vocabulary was considerably enlarged at the second stage of Soomaali differentiation, proto-Soomaali-II (see Ehret and Ali [1983] for this history and the evidence for it), by the palatalization of PEC $* k$ in following front-vowel environments. At the next stage of Soomaali differentiation, proto-Soomaali-III, all $/ c /$, both from PEC ${ }^{*} c$ and from palatalized $* k$, became $* \xi$, filling the slot in the system earlier left vacant by the falling together in proto-Soomaali-I of most 
PEC $* \xi$ and $*_{s}$ as PS $*_{s}$. A separate, but in many respects parallel, course of development also produced $/ \zeta /$ from PEC ${ }^{*} c$ in the Jiiddu branch of Soomaali (Ehret and Ali [1983] chart these courses of change with respect to palatalization of $* k$ ).

PEC * $c$ appears to have been a very common consonant indeed.

55. *cag- 'tip, top part'

HEC: Burji sag-a 'roof';

LEC: Oromo sagg-oo 'back of head'

The wider Cushitic evidence [Ehret 1987:141] confirms the reconstruction of PC and thus $\mathrm{PEC} * g$ (rather than $\mathrm{PEC} * g^{\prime}$ ) in this root.

56. *cal- 'to disapprove of'

HEC: Sidamo shal- 'to despise, scorn, dislike, loath';

LEC: Afar sal-i 'chastisement, correction, reproof'; sal-it- 'to chastise, reprimand, reprove' (stem plus Cushitic ${ }^{*} t$ continuative as denominative); Soomaali shall-aa 'to feel regret'; shall-ay 'regret'

57. *caal- 'to be narrow'

HEC: Sidamo shaal- 'to be narrow, slim, thin';

LEC: Soomaali shal-aw 'narrow place'

The vowel correspondence apparently reflects a regular sound correspondence of limited occurrence, seen also in \#79 below: PEC *aa > Soomaali $a / \# c_{-} l-$. The preceding root, \#56, evinces the correspondences for short PEC *a in this environment.

58. *cam- 'to rot, get wet'

HEC: Sidamo sham- 'to rot, go rotten; be wet, damp, humid'; Hadiya sam-a 'faulig, modrig'; Burji sam- 'to be drenched, become rotten with wet [sic]';

LEC: Soomaali: Bayso צem- 'to become rotten'; Oromo sam- 'to become mouldy, spoiled, become dirty'; Konso కam- 'to cool down, become numb'

59. *car- 'to grasp'

HEC: Sidamo sharr-am- 'to endeavor, to strive, to fight with one another, to make hand-to-hand struggle' (stem plus Cushitic ${ }^{*} m$ intr. extension, here with reciprocal connotation);

LEC: Soomaali: Jiiddu sar-aw 'to milk' (stem plus Cushitic *w inchoative); Arbore sar- 'to snatch' 
60. *carb-/*cirb-/*curb- 'thin stick'

LEC: Afar sarab 'long thin saplings used for building purposes' Jiiddu shuruw 'penis' (PEC ${ }^{*} b>w / V_{-}$in Jiiddu);

Yaaku sirp-i 'stick'

Northern Soomaali sarab 'ramaglia per costruzioni', lacking regular sound correspondence in having $|s|$ for required $|s|$ and exactly reproducing the meaning of the Afar reflex (which does show regular correspondence throughout), must be considered a loan from an Afar-related language.

61. *carrf-/*cirrf-/*currf- 'clump of hair'

LEC: Soomaali shaaruf 'peli di animale'; Jiiddu sharuuf 'lion's mane'; Tunni shuruf 'lion's mane'; NW Maay shuruf 'end of cow's tail';

Yaaku siririp 'white hair'

62. *caww- 'to go away, withdraw'

HEC: Sidamo shaww- $u$ yaa 'to withdraw, draw aside';

LEC: Soomaali shab-i 'to drive away, expel' (stem plus regular Soomaali $-i$ reflex of EC caus.)

63. *ca؟Y- 'to burn (intr.)'

HEC: Hadiya ${ }^{\prime} a$ '-iss- 'Licht anzünden' (stem plus caus.);

LEC: Soomaali shaac 'luce irradiata'

Gollango (Dullay) sa?a 'warm; Wärme' is a loanword, probably from the Konso group, by reason of its containing /R/ rather than required $*$.

64. *cerr-/*corr- 'to send away, take away'

HEC: Sidamo shorr- 'to drive away, chase away';

Yaaku -ser-en- 'to carry on back' (stem plus old Cushitic * $n$ extension of non-finitive action)

65. *cet- 'to be small'

HEC: Sidamo shet- 'to be in a miserable condition, be humbled, suffer'; shet-a 'little, small, despicable';

Dullay: Dobase, Gollango sett-e 'girl; daughter (not one's own)'

66. ' $c i b$ - 'to become motionless'

HEC: Sidamo shibb-i yaa 'to become stiff, stiffen (as the face for [sic] anger)';

LEC: Soomaali shib 'silence, quiet'; shibb-i 'to make silent' (stem plus caus. - $i$ ); shibb-an 'to be silent' (stem plus EC *-m- intr. extension > regular stem-final (n) 
67. *cig- or *cig'- 'to take loose'

HEC: Sidamo shigg-a '(removed) foreskin';

Dullay: Gollango $\Im_{i k}$ - 'loslassen'; Gawwada $Y_{i k}$ - 'to release'

68. * ciigg - 'to move by dragging'

LEC: Oromo sigig-oo 'sliding';

Yaaku -siik- 'to drag'

69. * $c i k$ '- 'to move a short distance'

HEC: Sidamo shiq- 'to approach, come near'; Hadiya siq- 'vorbeigehen; zur Seite treten'; siq-a 'near';

LEC: Oromo siq- 'to move a little; drag on; push on something'

Soomaali siko 'to move a little' shows the deglottalization of the velar and the presence of $/ s /$ (instead of regular $/ s /$ ), both typical of Afar and thus, like a large number of words in the "standard" Northern Soomaali, it must be considered a loanform of this root, borrowed from an extinct Afar-related language. The root has not yet been noted in Afar itself.

70. * cin- 'to attach'

HEC: Sidamo shinshin- 'to sew a piece of cloth; plait; gather in (the skirt)' (reduplicated stem); Hadiya Sin-e'e 'surroundings, neighborhood';

LEC: Soomaali shin-so 'to be attached to something'

71. *ciink'- 'to become thin, weak, slight'

HEC: Sidamo shiinq-a 'dwarf, small thing, little thing';

LEC: Soomaali shiiq 'to exhaust slowly (e.g. foam of liquid); to become weakened'; Oromo siiq-ee 'reed; thin person'

72. *ci?- or *cis- 'hurry'

HEC: Sidamo shi'-am- 'to hasten to do something' (stem plus EC * $m$ intr.);

LEC: Oromo $s i$ '- $a$ 'alertness, quickness'

73. * ${ }^{*} c k$ - 'to wind, twist (intr.)'

HEC: Sidamo shokk - 'to be crooked'; Hadiya sok- 'spulen';

LEC: Afar sok- 'to curl hair into ringlets' (men)

74. *cokk - 'to go away'

LEC: Oromo sokk- 'to go away';

Yaaku -sok-s- 'to remove, take away' (stem plus EC caus.)

75. *cok'- 'to loosen, break up'

HEC: Sidamo కooq-al-aam-o 'broken, not compact' (said of a kind of cake) (stem plus Cushitic $* l$ adj. suff. plus Cushitic n. suff. in ${ }^{*} m$; vowel length is not yet 


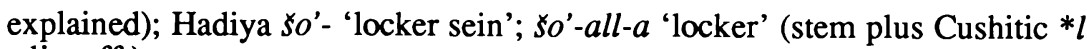
adj. suff.);

LEC: Soomaali, Garre, Tunni, Jiiddu §aq saq 'to sieve; sieve' (reduplicated stem); Oromo soq- 'to chip, weed, cut off, dig up'

Sidamo soq- 'to cut grass on threshing floor' fails to show expected / $\$$ / for PEC ${ }^{*} c$ and thus must be considered a loan in a technically narrowed sense from Oromo. The additional Sidamo meaning for soq-, 'to crush, smash', surely reflects a distinct course of lexical history, the confusing in Sidamo of two separate PEC roots *suk'- (\#39 above) 'to be knocked apart, pounded up', the expected outcome of which would have been *suq-, and *j'ok'- (\#165 below) the reflex of which should have been * soq-. A fourth root resemblant to these three in shape and meaning, but not confused with them in Sidamo, is \#78 below.

76. *colool- 'to remove, loosen (skin, bark, etc.)'

HEC: Sidamo sholool- 'to take the bark off a tree';

LEC: Afar saloo-t-, soloo- $t$ - 'to circumcise' (stem plus Cushitic $*^{*} t$ continuant extension with presumed elision of second $* l$ : ${ }^{*}$ solool-t- > soloot-); Oromo solool-oo 'tall tree without lower branches'

Burji ‘ool- 'to peel, strip' is a loanword from an Ometo language (Sasse [1982] citing Hayward, personal communication; and independently by the writer). The Ometo form itself can be considered a reflex of the same root seen in Eastern Cushitic, deriving through proto-Omotic from a common Afroasiatic base.

77. *cub- or *cub'- 'to spill'

HEC: Sidamo shup'-p'-i ass- 'to piss' (middle voice stem: *cub-plus *-d'- middle voice marker, ass- 'do');

LEC: Soomaali shub 'to pour'

78. *cuk'- 'to strike with a tool'

HEC: Sidamo shuq-un- 'to weed a field, hoe around a tree' (stem plus old Cushitic *n non-finitive extension);

LEC: Soomaali shuq-ee 'to prod, poke; to pound lightly to separate the chaff'

Hadiya sukun- and sukkun-, 'to weed,' both of which lack the required glottalic reflex ${ }^{*} k$ ' and one of which shows $s$ for expected $s$, are probable confusions of the HEC form of this root with Oromo sukkum- 'to weed,' the source of which remains to be satisfactorily established.

79. *cuul- 'to cut in pieces'

HEC: Sidamo shuul- 'to cut in little pieces';

LEC: Soomaali shulshul 'frange; mettere frange a qs.' (reduplicated stem) 
See \#57 above for the vowel sound correspondence present here.

80. *cur- 'to inhale'

HEC: Burji sur-aa 'salt-licking place for cattle';

LEC: Afar sur-uy 'odor, smell' (stem plus Cushitic *y n. suff.);

Dullay: Gawwada surr- 'to suck'; Saamakko sur- 'to suck'

The word sur 'neck' (semantics: locus of breathing), found in northern Soomaali dialects, probably comes from this root, but because of its attestation of $/ s /$ instead of the expected $/ S /$ it should be numbered among the numerous loanwords in standard Soomaali from an extinct Afar-related tongue.

81. *bac- or *b'ac- 'front'

HEC: Sidamo bassh-o 'before, in the past'

LEC: Afar bas-o 'forehead'

82. *baaccal- or *b'aaccal- 'to pass time enjoyably'

HEC: Hadiya bassal- 'den Tag verbringen';

LEC: Soomaali baashaal 'to divert oneself, amuse oneself; diversion, amusement'; NW Maay baashal 'story'

The Dullay form of this root (Harso, Dobase paasar-ko 'story' ) is a loan-word because it shows $/ s /$ rather than the required correspondent $/ S /$ (proto-Dullay ${ }^{*} c$ ). The significance of its attestation of root-final $/ r /$ in place of expected $/ l /$ is not clear. Possibly this feature reflects borrowing from an HEC language, in some of which a stem-final $* l>r$ shift appears. Within HEC, $/ s /$ for PEC $*_{c}$ is seen in Burji but not elsewhere.

83. *buc- or *b'uc- 'groin, crotch'

HEC: Sidamo bussh-e 'proper name of a woman in Sidamo tales';

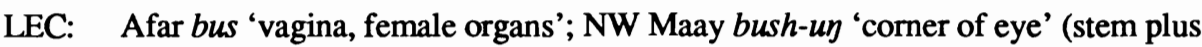
Cushitic n. suff. in $* n$ or $* m,>\eta / \_$in Maay masc. n.)

84. *daacc- $/ *$ duucc- 'to put over, put above'

HEC: Sidamo daassh- 'to spread (cement, metal on)';

LEC: Afar daas 'hut, Koranic school'; Soomaali daash 'verandah'; Jiiddu daash 'shelter in fields'; Oromo duucc- 'to cover, stop up';

Dullay: Dobase tas- 'bedecken'

85. *ficc- 'thick fluid'

LEC: Soomaali fiish 'pus produced from conjunctivitis';

Dullay: Saamakko picc-e 'whey'; Gollango fis-a 'whey' 
86. *gacc- or *g'acc- 'blemish, mark in the skin'

LEC: Soomaali gaash-i 'grosso neo; chiazza sul pelo di un animale; alone'; Oromo gacc-ii 'farm animal whose ear is split'

87. *gaaccan- 'shield'

LEC: Soomaali gaashaan 'shield'; Oromo gaaccan 'shield';

Dullay: Gollango kaasan-ko 'shield'

Burji gaazee 'shield' is probably not the same root, since no known Eastern Cushitic languages gives $/ z /$ as its reflex of $\mathrm{PEC} * c c$. But it could well be a borrowed form of another PEC root, *gaazz- 'shade', i.e. something that covers.

88. *goc- or *g'oc- 'to pull toward one'

HEC: Sidamo gosh- 'to pull, uproot, draw out'; Hadiya goš- 'to milk';

LEC: Soomaali gash-o 'to put on (clothes)'

89. *kacc- 'shoulder'

LEC: Soomaali: Rendille kac 'chest';

Dullay: Gollango has-itto, Gawwada xaš-ito 'shoulder'; Saamakko kacc-a 'shoulder'

Burji kacc-o and Arbore kacc 'shoulder' are loanwords, most likely from an earlier Dullay source. The form kac 'chest' in the Elmolo dialect of Arbore would appear, from its semantic identity with the Rendille reflex, to be a separate loanword from earlier Rendille. This root is not to be confused (contra Sasse [1982:112]) with PEC *kesf- 'chest'-well attested by Soomaali shaf (< earlier $*$ sef- < * esef < PS *kesef- by regular Soomaali-II palatalization of PEC ${ }^{*} k$ ), Konso kess- $a$, and Yaaku kehp-en, all meaning 'chest'-which differs in its stem vowel as well as its consonants. PEC *kacc-derives from a PC root for 'shoulder' also found in the Agaw branch of Cushitic [Ehret 1987:142], while *kesf- can with lesser confidence be connected up to another PC root [Ehret 1987:47, 98]. The skewed vowel correspondence in Harso heš-e 'shoulder' may have been caused by the influence of the resemblant Konsoid kess- $a$ (<*kesf-).

90. *kic S- 'to laugh'

LEC: Afar kixiixiq-t- 'to giggle' (stem partially reduplicated by *CVCVVC pattern as in \#24, \#137, \#166, and \#201, plus Cushitic *t continuative);

Dullay: Gollango kisa؟-, Gawwada kišas- 'to laugh'; Saamakko kica؟- 'to laugh'

The Afar reflex shows a voicing of $\mathrm{PEC}{ }^{*} c$ in the particular environment \#CV_VC, by a rule that, to produce modern Afar $x$, should have operated before PEC ${ }^{*} j$ ' (for which see $\$ 1.3$ below) fell together with $* d$ '. If the postulation [Ehret 1987] that the collapsing of PEC $* d^{\prime}$ and ${ }^{*} j^{\prime}$ took place in the common proto-Lowland East Cushitic ancestor language of Afar, Soomaali, Oromo, etc., 
is correct, then evidence of the limited voicing shift of PEC ${ }^{*} c$ noted here for Afar should be found eventually in other LEC languages.

91. *kiyyacc- 'to watch, gaze'

HEC: Sidamo keessh- 'to be late, await, linger' (semantics: 'to watch' > 'to wait (for)'); kecci yaa 'to look at with wide open eyes; to stare at fixedly';

LEC: Afar kiyaas- 'to measure'; Soomaali shiish 'sight; to look, fix the gaze on' (regular palatalization here: ${ }^{*} k>s h / \_i$ )

The evidence in this entry provides a basis for deciding the reconstruction of the medial segmental sequences in roots \#147, \#161, and \#162 below, where parallel sets of vowel correspondences obtain. Sidamo $/ \mathrm{cc} /$ in its second entry is taken to be the outcome of geminated ${ }^{*} c c$ (or Sidamo / $/ \zeta$ /) in the environment /\#CV_VC(see also \#181 below for the possible operation of the same rule, but where Sidamo / $\$ \$$ / has a different PEC source).

92. * $k^{\prime}$ 'ooc- 'to scrape (off)'

HEC: Burji $k$ 'oos- 'to peel'

LEC: Soomaali: Bayso oss- 'to dig'; Gidole k'osss- 'to weed';

Dullay: Gollango qoos- 'kratzen'

The Burji form here, because of its distinct meaning, is not easily derived as a loan from any of the languages in which PEC ${ }^{*} c$ regularly yields $/ s /$. On the basis of the parallel Burji outcome in root \#100 below, where again there is no obvious loan-source-and lacking any counter-examples as yet-PEC ${ }^{*} c$ is provisionally proposed to give Burji $|\zeta|$ in the limited environment of $l o(\mathrm{C})_{\text {. }}$. The Lowland East Cushitic cognates show a shared innovation, an underlying shift of application of the verb to the scraping off of the ground by human activity.

93. *lac- 'day'

HEC: Burji las-a 'day';

LEC: Gidole lałs 'sun, day'

94. *macc- 'drunkenness'; *macc-aaw- 'to get drunk'

HEC: Burji mass-aaw- 'to get drunk';

LEC: Oromo macc-ii 'drunkenness'; macc-aaw- 'to get drunk'; Konso maş-oo-d''to get drunk' (2nd stem plus EC middle voice extension)

The verb root comprises the stem *macc-plus the Cushitic inchoative in $* w$. Arbore macce 'intoxication' and maccoW- 'to get drunk' must be reckoned as loans, probably from Oromo, because the regular Arbore shape would be *mass(see \#188 below). Dobase (Dullay) mass-ad'- 'to get drunk', which fails to show 
the regular Dobase outcome / $\$ \zeta /$ for PEC ${ }^{*} c c$ and is thus also a loanword, may have been borrowed from Arbore before that language adopted its modern form of the root, or from early Burji.

95. *mic-/*muc-/*mac- 'to stick out, emerge out of'

( ${ }^{*}$ micc- $/{ }^{*}$ mucc- $/{ }^{*}$ macc- 'projection, pointed object')

HEC: Hadiya mis- 'Frucht bringen'; mis-a 'Frucht'; Burji miss-a, mus-aa 'penis';

LEC: Afar muss- $a$ 'small knife'; Bayso mas-a 'knife' (from non-geminated verb shape *mac-); maał-a 'horn' (from geminated noun shape *macc- by the usual Soomaali-group rule *VCC > *VVC/\#C_(V)\#); Oromo mucc-a 'teat (animal)'

96. *muc-/*mic- 'to chew slowly'

LEC: Afar mus-ay 'chewing the soft part of the bone' (stem plus Cushitic $n$. suff. in *y); Soomaali miishmiish-o 'to sip slowly' (reduplicated stem with geminant *c: $<*$ micc-);

Dullay: Dobase, Gollango mušo 'Frühstück'

The Soomaali version of this root requires reconstruction of an alternate shape with geminated final consonant, *micc-.

97. *tac- 'pleasant happening'

HEC: Sidamo tassh-i yaa 'to be pleasant'; tassh-i ass- 'to please' (ass- 'do');

LEC: Afar tass-a 'joy, gladness, happiness, pleasure'; Soomaali tash-o 'to free oneself from dependence on something; to decide on something to one's advantage'

98. * *'acc- 'to seep'

HEC: Sidamo t'assh-o 'river';

LEC: Soomaali dhash-uun 'secreted or oozed substance, sweat, secretion; to secrete, sweat' (stem plus Cushitic n. suff. in $* m>$ Soomaali $n$ word-final)

99. *t'ucc-/*t'uuc- 'string'

HEC: Sidamo t'ussh-o 'string, rope';

Yaaku t'oos-o 'bow string'

The Yaaku reflex requires the second of the two reconstructed stem shapes. For other examples of an apparent old EC alternance of ${ }^{*} \mathrm{CVCC}$ - and ${ }^{*} \mathrm{CVVC}$ - in roots, see \#135, \#137, \#183, \#200, and \#207 below.

\section{0. *warca 9 - 'rhinoceros'}

HEC: Burji wor $̌ a$ 'rhinoceros';

LEC: Oromo wors-eesa 'rhinoceros'; Konso orצ-ayta 'rhinoceros' (both Oromo and Konso add *-ayta n. suff. to stem, > Oromo -eesa); 
Yaaku orse', pl. orse'-en 'rhinoceros';
Dullay: Gollango orsas-te 'rhinoceros'

This reconstruction revises previous postulations of the root in both its consonants and its vowels. See \#92 above for justification of the inclusion of Burji as a regular cognate here, despite its attestation of $/ \zeta /$ for $\mathrm{PEC}{ }^{*} c$.

101. * Pac- 'here'; * Pacc- 'there'

LEC: Oromo as-i 'here,' acc-i 'there';

Yaaku as-e 'there (very far)'

102. *?ac- 'to lack'

LEC: Afar as- 'to be absent from'; Soomaali ash 'to not feel well' (i.e. lacking health); ashash 'to feel nausea, feel aversion' (reduplicated stem);

Yaaku as- 'to lack'

103. *?aac- or *Yaac- 'to be wet'

HEC: Hadiya aas- 'to be wet'; aasal 'wet' (stem plus Cushitic adj. suff. in *l);

LEC: Soomaali: Jiiddu aash-uun, Garre, Tunni, NW Maay ash-uun 'large water pot' (stem plus noun suffix in $* n$; pharyngal feature is lost in these languages)

Standard southern Soomaali also has the root in the shape aashuun, but since that dialect has probably borrowed the word from one of the southern Soomaali languages in which the pharyngal feature has been deleted, it remains unclear whether this root begins in PEC *? or * .

104. * Yac-/* Yic- 'to shine, glow'

LEC: Afar qas- 'to be red'; Soomaali casho 'giorno, arca delle ventriquattro ora a partire dal tramonto'; Oromo icc-im- 'to produce fire by rubbing sticks' (stem plus Cushitic * $m$ intr. extension);

Yaaku is-e 'smoke'

The word cas(aan) 'red,' replacing the proto-Soomaali root for 'red', *guddeet, only in the Northern Soomaali dialects of the Horn of Africa, is a loanword, adopted from an extinct language closely related to Afar [Ali 1985].

Seven further examples of PEC roots attesting ${ }^{*} c$ appear among the data for the consonants ${ }^{*} g,{ }^{*} x$, and $*_{\eta}$ discussed below (see \#118, \#134-136, \#187, \#188, and \#236). An eighth root containing root-initial *c, PEC *cank-/*cink- 'back,' can be found in previously published materials [Sasse 1976]. There it was proposed to begin in $\mathrm{PEC}^{*} s$, based on a semantically uncomfortable fit between it and an Oromo word beginning in $|f|$, the usual Oromo correspondent of PEC ${ }^{*} s$. Leaving aside the questionable Oromo connection, the solid EC evidence is ambiguous as to whether ${ }^{*} s$ or ${ }^{*} c$ should be reconstructed. But the wider comparative Cushitic materials show the etymon to be $\mathrm{PEC}{ }^{*} c$, the shape ${ }^{*}$ cank- 
$I^{*}$ cink- being the usual and expected Eastern Cushitic outcome of the PC root ${ }^{*} d z a n k^{w}-{ }^{*} d z i n k^{w}$ - 'back' attested also in Beja and Southern Cushitic [Ehret 1987:140].

For several PEC roots the evidence available allows either ${ }^{*} c$ or ${ }^{*} s,{ }^{*} c$ or $* \xi$, or, in two cases, ${ }^{*} c,{ }^{*} s$, or ${ }^{*} \xi$ to be reconstructed:

105. *cagaal- or *sagaal- or *sagaal- 'nine'

LEC: Afar sagaal 'nine'; Soomaali sagaal 'nine'; Arbore saagal- 'nine'; Oromo sagal 'nine';

Yaaku saakal 'nine'

The failure of regular sound correspondence in the word-initial phoneme here is surely attributable to an assimilation shift effected by the usually sequential utterance of 'nine' after 'eight'. The root for 'eight' had PEC *s as its initial segment, which in this particular case was regularly maintained as $/ s$ / in each of its Eastern Cushitic reflexes (see \#14 above). Depending on whether the sequential assimilation of the initial sibilant in PEC 'nine' to the first sibilant of PEC 'eight' took place in Oromo (with the usual shift of PEC *s > Oromo /f/ blocked by the occurrence of initial $/ s$ / in 'eight'), or in Yaaku (with expected $/ S /$ $<$ PEC * $\xi$ assimilated to the initial $* s$ of 'eight'), or in Soomaali (with expected $/ \$ /$ $<$ PEC ${ }^{*} c$ similarly assimilated to the $/ s /$ of 'eight') - any one of the three sibilants might have been the original initial consonant in PEC. The vowel reconstruction chosen here presumes a metathesis of the long and short vowels in Yaaku and in Arbore, in the latter language probably through the influence of the extinct Yaaku-related tongue which, in a number of other cases, can be shown as the source of loanwords in Arbore.

106. *-cak-/*-cik- or *-sak-/*-sik- 'to be lightweight'

HEC: Burji צak-an-ee 'light (of weight)' (stem plus Cushitic adj. suff. in * $n$ );

LEC: Afar -isissik- 'to be fast, light, easy, lightweight' [Hayward, p.c., to Sasse 1982]; 'to hurry' [Parker and Hayward 1985] (partially reduplicated stem); Konso ‘akk- 'small'

This correspondence set was noted by Sasse [1982], following up on a personal communication from R. J. Hayward. Konso $/ \$ /$ seems to be its regular reflex of PEC *c (see \#58, \#92-94, and \#100 above). Burji / $\$ /$, however, regularly derives from PEC $* \xi$, whereas PEC ${ }^{*} c$ is usually represented by Burji $/ s /$. Either Burji or Konso (or possibly both), it must be argued, has borrowed its form from some as yet unidentified EC source language.

107. *cak'r- or *sak'r- 'hips'

LEC: Arbore sak'ar 'hips, waist region';

Yaaku saqar 'vagina' 
108. *caal- or *saal- 'oryx'

LEC: Oromo saal-a 'oryx';

Dullay: Gollango saal-to 'oryx'

If the Burji reflex saal-a is not a loanword, then the reconstruction is clearly * caal-. But Burji has adopted so many words from Oromo in recent times that the identity of its form with that of Oromo makes it suspect here.

109. *camb'- or *samb'- 'young man'

LEC: Afar samb-o 'genitals of male';

Dullay: Saamakko samb'-o 'son (of)'; Gollango samp-o 'Junge'

Some forms of this root in Dullay may have to be explained as loans from Omotic (as proposed by Hayward [1989]), but the items cited here all show unexceptionable EC correspondences.

110. *cer- or *ser- or *ser- 'kudu'

LEC: Afar sar-a 'large kudu'; Arbore ser-em 'kudu' (stem plus Cushitic n. suff. in $\left.{ }^{*} m\right)$

111. *coonc- or *soonc- 'to make a whirring sound'

HEC: Sidamo shoossh- 'to roar' (of waves on the lake);

LEC: Oromo sons-a 'wasp'

Burji sunsi 'wasp' is a probable loan from Oromo.

One further root in which either ${ }^{*} c$ or $* \zeta$ might be reconstructed appears below in the evidence for PEC ${ }^{*} g$ ' (\#146). And at least one root previously postulated with initial * $\xi$ [Sasse 1975, 1976, and 1979], * «eeb- or *ceeb- 'leather strap', is ambiguous on present evidence as to whether PEC * ${ }^{\zeta}$ or ${ }^{*} c$ is the correct representation of its sibilant.

1.2. Proto-Eastern Cushitic ${ }^{*} g$ '. The necessity of reconstructing PEC ${ }^{*} g$, distinct from the well accepted PEC $* g$, is amply supported by the evidence from the Dullay and Yaaku subgroups of Eastern Cushitic. In Lowland Eastern Cushitic and Highland Eastern Cushitic languages * $g$ and $* g$ ' have fallen together as $/ g /$. But in the other two subgroups - except for several instances in which ${ }^{*} g$ ' has been confused with Dullay's and Yaaku's unusual implosive uvular reflex of PEC * $k$ ' - the two consonants have retained distinct outcomes. In Yaaku and most Dullay dialects, PEC $* g$ has devoiced to $/ k /$ as part of a general rule devoicing the simple PEC obstruents, inter alia shifting $* b$ to $/ p /,{ }^{*} d$ to $/ t /$, and $*_{z}$ to $/ s /$. PEC ${ }^{*} g^{\prime}$, on the other hand, follows the pattern of the established PEC voiced glottalic $* d$ ' in remaining voiced in both Dullay and Yaaku. In Yaaku and some Dullay dialects it is overtly articulated as an implosive-hence the need to reconstruct it 
as glottalic also in PEC. In one Dullay dialect, Saamakko, the devoicing rule did not operate, and as a result PEC ${ }^{*} g$ persists there as $/ g /$, while the posited PEC * $g$ ' indeed yields $/ g \%$.

One sound shift affecting medial non-geminant ${ }^{*} g^{\prime}$, devoicing it to ${ }^{*} k$ when the preceding consonant is a sibilant, appears to be diagnostic of the Lowland East Cushitic branch (examples in roots \#136, \#146, \#148, and apparently \#145). Because the voicing distinction has been lost in post-vocalic position in Soomaali, the Soomaali data is non-determinative for this shift, e.g. \#144 for which only a Soomaali example from Lowland East Cushitic is known. Afar also shows devoicing of ${ }^{*} g$ ' in its single case here of the environment $\# b V_{-}-\#$ (\#133); whether this might be a general Afar rule affecting pre-Afar $* g$ from both PEC ${ }^{*} g$ and ${ }^{*} g$ ' remains to be studied.

\section{2. *g'ab-/*g'ib- 'to lie still'}

LEC: Afar gabb-oow- 'to wait a long time' (stem plus Cushitic $*_{w}$ inchoative); Soomaali gaggab 'to be unconscious'; Oromo gab 'still, calm, stopped'; gaggab- 'to faint, become unconscious';

Dullay: Saamakko g'ipp- 'to sleep' (gemination as durative?)

The South Lowland East Cushitic languages Soomaali and Oromo share an innovated form by reduplication, *gaggab- 'to be(come) unconscious'; it may be an assimilated version of a once fully reduplicated shape *gabgab-.

\section{3. *g'aad'- 'to observe'}

LEC: Afar gaax- 'to guard, protect';

Dullay: Dobase gaad'-, Gollango g'aad'- 'denken (an)'

114. *g'ahr- 'hard covering'

LEC: Afar gacar 'outcrops of crumbly rock, rocky terrain';

Yaaku geher-oni 'cowry shell'

115. * $g$ 'al- 'to bend, curve'

HEC: Sidamo gangal-at- 'to roll up (intr.)' (partially reduplicated stem plus Cushitic * $t$ continuative extension);

LEC: Afar gal-e 'corner'; Soomaali gal 'halo of light which forms around the full moon some days of the month';

Dullay: Dobase gal-, Gollango g'al- 'biegen'

116. * $g^{\prime}$ an-/*g'un- 'to hit, strike'

HEC: Sidamo gan- 'to beat, hit, strike';

LEC: Soomaali gan 'to strike (with arrow or the like); to fling';

Dullay: Dobase gun-d'-, gon-d'- 'brechen, zerbrechen'; Gollango g'on-d'-, gun-d''zerbrechen' 
Dullay reflexes add the Eastern Cushitic * $d^{\prime}$ middle voice extension to the verb root, shifting the focus of action from the hitting to its effects.

\section{7. * $g^{\prime}$ 'ant- 'to give milk'}

LEC: Soomaali gand-al 'skin of muzzle of dead calf used to get cow to let down her milk' (stem plus Cushitic n. suff. in *l);

Dullay: Harso gan-ce, Gollango g'ant-e 'udder'

Stem-final ${ }^{*} t$ has been assimilated to the Dullay ${ }^{*} t$ feminine gender suffix in Harso $(\mathrm{PEC} * t>$ Harso $/ c /)$

118. *g'eecc- 'big, large, great'

HEC: Sidamo geessh-a 'stature, breadth, height, dimension';

Dullay: Dobase geeš-akko, Gollango g'ees-akko 'Greis'

119. * $g$ 'er- 'to call out'

LEC: Soomaali jar 'gioco simile alla dama' (*ger- > ${ }^{*}$ jer- > jar);

Dullay: Dobase ger-is- 'zujubeln' (stem plus EC caus.)

Oromo geerar- 'to sing a kind of song,' Soomaali geeraar, for a kind of war song, and Sidamo geeraar - 'to chant war songs; to utter war boasts' clearly reflect the diffusion of a form of this root by borrowing. The source is unknown, but the lengthening of the stem vowel suggests an underlying shape *gerraar-, with the CVCaaC- vocalization pattern of reduplication, e.g. instances in \#10 and \#15 above) and a *VCC $>* V V C$ shift such as occurs regularly in Afar and Soomaali, among others (see $\$ 3$ below). Soomaali cannot be the source, however, since its form lacks the regular Soomaali palatalization of ${ }^{*} g$ before a front-vowel.

120. * $g^{\prime}$ er - 'to wear out'

HEC: Sidamo geer-co 'old person';

LEC: Oromo jaar-sa 'old person'; Konso kers- 'to be old';

Yaaku -gere'- 'to be tired'

The Yaaku form requires this revision of the root shape ${ }^{*}$ ger - given in Sasse [1979].

121. *g'id'd'- 'flesh'

LEC: Soomaali jiidh 'polpa di carne';

Dullay: Harso, Dobase gid'-a, Gollango g'id'd'-e 'mageres Fleisch' 
122. * $g$ 'im- 'to slice, cut into'

Yaaku -gem- 'to notch';

Dullay: Saamakko g'im- 'to reap'

123. *g'in- 'to twist (string, rope, etc.)'

LEC: Afar gin 'to braid, twist, wind';

Dullay: Gollango g'in-t-o 'Perlenband' (stem plus Cushitic n. suff. in *t)

124. * $g$ 'iin- 'to stay in place'

125. * $g^{\prime}$ iind-/*g'aand- 'residence' (\#124 plus $*^{*} t \mathrm{n}$. suff. with voicing assimilation?)

HEC: Hadiya giin- 'to become steady, firm; come to rest'; Burji gand-i 'enclosure for cattle and settlement outside the village;

LEC: Afar gaant-a 'village'; Oromo gand-a 'village';

Dullay: Harso, Dobase gint-e, Gollango g'int-e 'Hof (des Gehöfts)

For Afar voicing/devoicing alternations in nasal clusters, see also \#22 above and \#130 below.

126. * $g$ 'obl- 'to cut off'

LEC: Soomaali gobol, gabal 'piece, part; portion';

Dullay: Dobase gopol- 'to castrate'; Gollango g'opol-ko 'billy-goat' (goat wether?)

127. *g'oh-/*g'eh- 'to become big, grow'

LEC: Arbore geh- 'to become fat';

Dullay: Saamakko $g$ 'oh- 'to become big, grow'

128. *g'ub- 'to make, build'

HEC: Sidamo $g u w-, g u b b$ - 'to produce, put out' (of plants, animals)'

LEC: Afar gub 'permanent residence'

Dullay: Harso gup-, Gollango g'up-ad'- 'to build'

129. * $g$ 'uh-/*g'ah- 'to flow'

LEC: Afar guc-um 'water from a geyser' (stem plus Cushitic deverbative in ${ }^{*} m$ ); Soomaali *guh 'long rains'; Arbore guh 'year, rainy season'

Dullay: Saamakko $g$ 'ah-am- 'to flow'; $g$ 'ah-is- 'to pour'

This entry corrects and revises an earlier postulation (in Sasse [1979]).

130. * $g$ 'unt- 'thing that sticks out'

HEC: Sidamo gunt-ut- 'to bud (new leaves)'; gunt-ut-a 'bud' (stem plus Cushitic *t continuative extension apparently as denominative); 
LEC: Afar gund-us- 'to suck a lot of milk from the breast' (stem plus Cushitic causative as denominative);

Dullay: Gollango g'unt-e 'Männliche Geschlechtstrophäe'

The Afar reflex can be understood as deriving from the noun in a narrowed application to a particular kind of protruding thing, the breast. Oromo gunt-ut-a 'breast (young),' because of its identical morphology to that of the self-derived Sidamo noun reflex for 'bud,' may be a loan from an HEC language, but its figurative use may reflect the semantic influence of a lost Oromo form of the root that bore an earlier LEC meaning seen also in the Afar reflex.

131. *g'urr-/*g'irr- 'to put together, connect'

HEC: Sidamo gur- 'to collect, assemble';

LEC: Soomaali guur 'marriage'; Oromo guur- 'to bring together';

Yaaku -girgir- 'to sew' (reduplicated stem)

The lack of expected gemination in Sidamo needs explaining.

132. * $g$ 'uuৎ- 'to cry loudly'

LEC: Afar guq-to 'complaining' (stem plus Cushitic * $t$ n. suff.);

Dullay: Saamakko g'uus- 'to roar, bellow'

133. bog'- 'to finish, bring to an end'

HEC: Sidamo bogg-iy-aa 'completely' (stem plus *y adj. suff.)

LEC: Afar bak- 'to be finished'; Soomaali bog 'to finish, complete';

Dullay: Harso, Dobase pog-, Gollango pok- 'to kill'; Saamakko bog'- 'to kill'

134. *caag'g'- 'to stick into, penetrate'

LEC: Afar saag-it- 'to copulate (of sheep)' (stem plus Cushitic $* t$ continuative extension); Oromo saag- 'to thicken, fill in (esp. wall), reinforce';

Yaaku -saag- 'to hunt (with spear or bow and arrow)'

Geminate ${ }^{*} g$ ' is reconstructed to account for LEC retention of voicing in the velar stop after a sibilant.

135. * cig'g'-/*cag' $g^{\prime}$ - 'to be strong (of taste, ability, condition)'

HEC: Sidamo shagagg-i yaa 'to set the teeth on edge (sour, acid food or drink)' (partially reduplicated stem);

LEC: Afar sigg- $a$ 'strength';

Yaaku seeg-u 'bitter, sharp, fierce' 
The Yaaku reflex presumes an alternate root shape *ciig'-; for other cases of old Eastern Cushitic ${ }^{*}$ CVCC-/*CVVC- alternances, see \#99, \#137, \#183, \#200, and \#207.

136. *cuug'- 'to rub, scrub'

LEC: Afar suksuuk- 'to scrub hard to remove dirt or tarnish' (reduplicated stem); Arbore suk-ad'- 'to knead' (stem plus EC middle voice extension); Oromo sukk-uum- 'to rub, massage, knead' (stem plus Cushitic * $m$ intr. extension);

Yaaku -suug-s- 'to rub' (stem plus EC caus.)

Burji sukum- or sukkum-, 'to squeeze' or 'to rub, stroke' (according to different recorders), seems visibly a loanword from Oromo. The reason for the loss of vowel length in the Arbore reflex is unclear.

137. *dig'g'-/*dug'g'- 'to pull off'

HEC: Sidamo diig- 'to demolish, pull down'; duug- 'to scrape, tan, scratch'; Hadiya duug- 'to peel enset';

LEC: Oromo duguug- 'to strip off';

Yaaku -tig-in-s- 'to remove' (<*tig-im-s- or *tig-in-s-, stem plus either Cushitic ${ }^{*} m$ intr. or ${ }^{*} n$ non-finitive extension plus EC caus.)

The HEC reflexes imply an alternative stem shape, ${ }^{*}$ diig- $/ * d u u g-$, with long vowel instead of long consonant. See roots \#99, \#135, \#200, and \#207 for other indications of such alternances in early Eastern Cushitic. For the CVCVVCvocalization pattern, noted here in the Oromo reflex, see also \#90 above and \#166 and \#201 below.

138. *d'ag'- 'to engage in slander'

LEC: Afar xag- 'to revile, slander';

Dullay: Saamakko d'ag'-is- 'to insult' (stem plus EC caus.)

139. *fug'- 'to inhale/exhale'

HEC: Sidamo fug-am- 'to be choked, stifled, deprived of air' (stem plus Cushitic *m intr. extension = passive);

LEC: Afar fug-ut- 'to kiss' (stem plus Cushitic * $t$ continuative extension);

Dullay: Dobase fug- 'to blow (with the mouth)'

140. *hag'- 'to make as if to do something'

LEC: Oromo $a g$ - $a d$ ' $d$ '- 'to menace, threaten' (stem plus EC $* d$ ' middle voice extension);

Yaaku -eh-heg-um- 'to tease' (Yaaku benefactive plus stein plus Cushitic *m intr.)

The fronting of PEC $* a$ in Yaaku requires the reconstruction of pharyngeal $* \hbar$. 
141. *laag'- 'to return (tr.)'

LEC: Afar lagg-oy-is- 'to reconcile' (stem plus Cushitic * $y$ inchoative plus EC caus.);

Dullay: Saamakko laag'- 'to return (something)'

142. *lig'- 'to rise up'

LEC: Afar lig-a 'top layer of cream (on milk)'; Soomaali lig 'erect and rigid in position';

Yaaku lege, pl. legep-a 'hump' (<*lig'-ib-, stem plus Cushitic and Afroasiatic *b animate deverbative suffix); leg-ey 'large bird (gen.)' (stem plus Cushitic deverbative suff. in *y);

Dullay: Gollango lik- 'aufgehen (Sonne, Mond)'; Saamakko lig'- 'to go out'

143. *mag'-/*mug'- 'to flow out'

LEC: Soomaali mag-ay 'hole in ground where water stagnates' (stem plus Cushitic *y denominative suffix); magg-ow 'avere una montata lattea (di animale)' (stem plus Cushitic $*_{w}$ inchoative);

Yaaku -mug-ur- 'to leak' $\left(<* m u g g-u r-\right.$, stem plus either ${ }^{*} r$ n. suff., with verb as back-formation from old noun, or else Afroasiatic ${ }^{*} r$ diffusive extension for which see Ehret [1989]); mug-ur-en 'urine' (verb stem plus n. suff. or number marking in ${ }^{*} n$ );

Dullay: Harso, Dobase mag- 'ausgiessen'

144. *sig'- 'to scrape (against)'

LEC: Soomaali sig 'to graze (someone or something)';

Yaaku seg-il 'nail, claw' (stem plus Cushitic n. suff. in *l)

145. *sozzog'- 'father-in-law'

LEC: Soomaali soddog 'father-in-law'; Arbore soh 'in-law' Oromo sodd-aa 'in-law';

Yaaku sosok, sosog 'father-in-law';

Dullay: Saamakko zoog'-o 'father-in-law'

See \#13 and \#14 above for parallel examples of the conflation of sequential PEC $*_{s}$ and $*_{z}$ in first and second consonants positions in Saamakko and for Oromo maintenance of PEC $*_{s}$ as $/ s /$ in such environments. The lenition of ${ }^{*} g$ ' visible in the Arbore and Oromo forms of the root are probably attributable to the

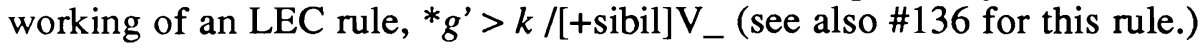

146. *sig'- or *cig'- 'to fart'

LEC: Afar siksik-a 'wind in the stomach';

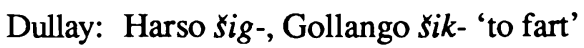


Presence of $/ g /$ in Harso is determinative of the reconstructibility of proto-Dullay ${ }^{*} g^{\prime}$. Gollango, although it consistently has $\left[g^{\prime}\right]$ word-initially for ${ }^{*} g^{\prime}$, normally devoices verb-stem-final * $g^{\prime}$ to $[k]$, e.g. \#133 and \#142.

\section{7. *t'iyag'- 'to bleed; blood'}

HEC: Hadiya t'eeg-a 'blood'; Burji c'eej-i 'blood';

LEC: Soomaali dhiig 'blood'; Arbore d'iik'- 'to bleed'; d'iik' 'blood'; Oromo d'iig- 'to bleed'; d'iig-a 'blood'; Konso d'iig-a, Gidole d'iig 'blood';

Yaaku t'ig-is-o' 'tsetse-flies' (stem plus Cushitic caus.; semantics: from the feeding habits of tsetse-flies);

Dullay: Harso, Dobase, Gawwada c'ax-te 'blood'; Gollango k'eek-te, Gawwada Dalpena $k$ 'eq-te 'blood'; Saamakko c'eg'-de 'blood'

For the same vowel correspondence between South Lowland and Highland East Cushitic languages (SLEC $* i i=\mathrm{HEC} * e e$ ), and for the evidence on reconstructing the PEC medial sequence ${ }^{*}-i y a$ - as its source, see \#91 above. The Dullay correspondences themselves presuppose a pre-proto-Dullay diphthong $\left({ }^{*}\right.$-ay- or *-ya-) as their etymon, independently supporting the PEC reconstruction of the medial segments of the root. The various vowel outcomes in Dullay dialectsHarso, Dobase, and Gawwada /a/ versus Gollango /ee/ and Saamakko and Gawwada Dalpena /e/-make it clear that, even in proto-Dullay, the diphthong had not yet fully resolved itself into a monophthong. Saamakko preserves the original articulation of the final consonant, devoiced elsewhere in Dullay in this environment and hence yielding variously $|x|,|k|$, and $|q|$.

The palatalization shift, HEC ${ }^{*} t^{\prime}>$ Burji $c^{\prime} / \#_{-}[+$front], is quite regular and is well attested in the available evidence (in particular Sasse [1982], although not recognized in the discussion there of Burji c'eeji). And Arvanites [1990] shows that $/ d^{\prime} /$ is commonly the outcome of PEC * $t^{\prime}$ in the limited environment /\#_i(i)Cin both Konso and Gidole. PEC ${ }^{*} t^{\prime}$, however, normally produced PD ${ }^{*} t^{\prime}$ rather than, as it did in this case, ${ }^{*} c^{\prime}$ (in Gollango and Gawwada Dalpena, PD ${ }^{*} c^{\prime}>/ k^{\prime} /$ ). Relating the Dullay forms to the rest of the EC reflexes therefore requires postulating the palatalization of ' $t$ ' in the restricted but especially powerful environment for such a shift, /\#_iyaC-as implied by the vowel correspondences outside Dullay: to wit, *t'iyag'- > *t'yag'- > *c'yag'-.

The Gawwada Dalpena $/ q /$ for ${ }^{*} g$ ' exemplifies an alternate history for $* g$ ' sometimes seen in the Dullay dialects-namely, the early development of occasional free alternances between those two implosive consonants. The Arbore reflex shows a distinctive outcome, reflecting a rule of the probable form $* g>k$ ' /\#CV_-\#, where $C$ is undefined as yet and ${ }^{*} g$ derives from the PLEC collapsing of $\mathrm{PEC}^{*} g$ and $* g^{\prime}$ ( see also Arbore -fek' 'far' under \#2). 


\section{8. *zog'- 'elephant'}

LEC: Afar dak-an-u 'elephant' (stem plus Cushitic n. suff. in *n);

Yaaku sog-om-e 'elephant' (stem plus Cushitic n. suff. in *m)

Yaaku vowel outcome implies ${ }^{*} z o g^{\prime} g$ 'ome, with ${ }^{*} g$ ' geminated perhaps in connection with the morphological operation of adding a noun suffix.

\section{9. *?aang'- 'bird'}

Yaaku $\eta g$-ay 'small bird (generic)' (stem plus Cushitic n. suff. in *y);

Dullay: Harso, Dobase aag-icce 'wild animal, bird'; Saamakko aag'g'-itte 'bird'

The shift, *?VN- > N- /\#_CV, appears to be a regular sound change in Yaaku, for which see also \#222 below.

The overall correspondence patterns show that, unless either the Dullay or Yaaku reflex of a root is known, one cannot be sure whether PEC ${ }^{*} g$ or ${ }^{*} g^{\prime}$ is to be reconstructed. This datum means that a number of roots so far recorded only from HEC and LEC languages and previously proposed to contain $* g$ may need to be reattributed. Among these are PEC *gabn- or * $g$ 'abn- 'dainty'; *gat- or *g'at- 'to sell'; *gawraS- or *g'awraS 'to slaughter'; and *geYl- or *g'eYl- 'to love.' Three roots where either ${ }^{*} g$ or ${ }^{*} g$ ' is possible also appear in the evidence presented above for PEC *c (\#67, \#86, and \#88).

1.3. Proto-Eastern Cushitic ${ }^{*} \boldsymbol{j}$ '. One other voiced obstruent, ${ }^{*} \boldsymbol{j}$, needs also to be added to the PEC inventory. In Highland East Cushitic and Dullay, its reflexes are consistently palatal (or pre-palatal), but not normally glottalic nor in many cases even plosive. Two strong pieces of evidence show, however, that this consonant was indeed originally an implosive stop. First, in Yaaku it did produce a palatal implosive $/ j /\left(\left[j^{\prime}\right]\right)$; second, in the Lowland East Cushitic languages its reflexes fell together everywhere with the recognized voiced glottalic ${ }^{*} d$ ' of PEC. This particular shift is argued in Ehret [1987] to be one of the diagnostic shifts attesting the validity of Lowland East Cushitic as a distinct genetic subgroup of Eastern Cushitic.

The scheme of correspondences supporting PEC * ${ }_{j}$ ' is the following:

$\begin{array}{cccccccccc}\text { PEC } & \text { Afar } & \text { Soomaali } & \text { Arbore } & \text { Oromo } & \text { Sidamo } & \text { Hadiya } & \text { Burji } & \text { Yaaku } & \text { Dullay } \\ *^{\prime} & x\left(d^{\prime}\right) & d h\left(d^{\prime}\right) & d^{\prime} & d^{\prime} & s h(\xi) & c & d^{\prime} & j & s, j\end{array}$

The Hadiya outcome is also attested in the evidence presented earlier for the overall proto-Cushitic reconstruction [Ehret 1987:152-162]. Burji, interestingly, shows $/ d^{\prime} /$ as its reflex of this consonant, mirroring the shift elsewhere diagnostic of Lowland East Cushitic. In Dullay, $/ j /$ is the Saamakko outcome in at least some non-front vowel environments; but see \#156 for an example of Saamakko $\zeta$ 
/\#_ee). The other dialects all show $/ \zeta /$, or possibly in a few cases $/ y /$ [Hayward 1989].

150. *j'abbal- 'to be agitated'

HEC: Sidamo shabbaar- 'to be troubled, agitated';

LEC: Afar xabal-, dabal- 'to wave arms and sway in dance' Soomaali dhabaal-ee 'incitare qn.'

151. *j'af- 'stir (tr.)'

HEC: Sidamo shaf- 'to shake, stir, toss';

LEC: Soomaali dhaf 'mescolare qs., miscelare qs.'

152. *j'ah-/*j'ih- 'to avoid, keep away from'

LEC: Afar xac-ar- 'to leave habitations to seek grazing' (stem plus probably Cushitic ${ }^{*} r$ n. suff., with verb as back-formation from noun); Soomaali dhax 'to not return home, stay far from home'; Arbore $d$ 'eh- 'to escape'; Oromo $d$ '-iis- 'to leave (tr.)' (stem plus Cushitic caus.);

Yaaku -jih- 'to fear'

153. *j'allal- 'to be(come) wet and cold'

LEC: Soomaali dhalaal 'liquefarsi, scogliersi, fondersi; circolare (sangue)'; dhalaalis-o 'freddo molto intenso, gelata';

Dullay: Harso, Dobase, Gollango salal- 'kalt sein'

154. *j'a ${ }^{-}$- 'to descend from a height'

HEC: Sidamo sha'-e 'elevated post for the guardian of the field; top of the house';

LEC: Afar xaxxaq 'rock fall, precipice' (reduplicated stem); Soomaali dhac 'to fall'; dhaadhac 'scendere da qs. (altura)'; Oromo $d$ 'aw-, d' $a$ '- 'to fall on'

155. *j'aa - $^{*}{ }^{\prime}$ 'ii - 'to blow, expel air'

LEC: Soomaali dhac 'to blow (of wind)'; Arbore d'ee?- 'to belch';

Yaaku nuka -jii'- 'to sneeze' (nuka 'nose')

156. *j'eeg'- 'to rise, swell, stick up or out'

HEC: Burji d'eeg-i 'tail';

LEC: Soomaali dheeg 'parte superiori di qs.; luogo elevato';

Dullay: Harso, Dobase Yeeg'-, Gollango Yeeg'-, Yeek'- 'schwanger sein; tragen; haben' (the latter two meanings can be understood as transitive use, 'to rise' > 'to lift, pick up')

Saamakko also has seeg'- 'to have, get, become pregnant', indicating that either in some environments (front-vowel?) Saamakko has $|\zeta|$ for PEC $* j$ ', or else this particular word is a loan from another Dullay dialect. 


\section{7. *j'ej'j'- 'to intend, expect, want'}

HEC: Burji d'eed'- 'to become jealous'; d'iid'-iy- 'to covet' (see Sasse [1982] for plausible explanation of vowel-raising shift here);

LEC: Afar xaax- 'to intend to, almost do, nearly happen'; Soomaali dherer 'to wait anxiously for'; Oromo d'arr-a'- 'to crave' (stem plus probably form of EC middle voice extension, ${ }^{*}-d^{\prime}$-);

Yaaku -jej- 'to want, need'

The Soomaali non-initial $/ r /$ might be explained by its having been recorded in a southern standard Soomaali context, in which PLEC $* d^{\prime}>r / V_{-}$, except that the Oromo version of the root also shows $/ r /$. It seems more probable, thus, that a shared South Lowland East Cushitic dissimilation, ${ }^{*} d^{\prime} d^{\prime}>{ }^{*} r r / d^{\prime} \mathrm{V}_{-}$, not found in Afar of North Lowland, is present here.

158. *j'iij'- 'to secrete'

LEC: Afar xiix-oxx-a 'semen' (stem plus geminated EC * $d$ ' middle voice extension, 'be secreted');

Yaaku -jeej- 'to lay eggs'

159. *j'ill- 'to clench teeth'

HEC: Sidamo shill-i ass- 'to set the teeth on edge (sour food)' (ass- 'do');

LEC: Soomaali dhiil 'to clench (teeth, in facing danger)'

160. *j'im?- 'to ooze, seep'

HEC: Hadiya cin-e 'fatal calf disease beginning with diarrhea'; ciin-s- 'to squeeze out' (stem plus Cushitic caus.);

LEC: Afar xim-o 'sorrow, tears'; xiim-hee 'to pour a small quantity' (hee 'put'); xiimis- 'to rain heavily' (stem plus caus.); xim-oom-is- 'to drip down' (stem plus probably ${ }^{*} w$ inchoative plus Cushitic $* m$ intr. extension plus Cushitic caus.); Soomaali dhiin 'succo, umore; resina; secreto (di un vegetale); secernare (un succo, umore, resina, ecc.)'; Oromo d'im'-uu 'leak'; d'im'-is- 'to leak' (stem plus caus. as denom.)

161. *j'iyyab- or *j'iyyab'- 'to set, lower, put low'

HEC: Hadiya cebb-a 'unten'; Burji d'eeb- 'to put, place';

LEC: Afar xixxib 'humbleness, lowliness' (partially reduplicated stem); Soomaali dhiibdhiib 'stare seduto con le gambe stese per terra' (reduplicated stem); Oromo d'iib-uu 'valley';

Dullay: Gollango siipp-atte 'evening' (semantics: from setting of sun)

For parallel vowel correspondence patterns see \#91 and \#147 above and \#162 following. The vowel correspondences rule out derivation of the Burji reflex from PEC *d'abb- or *d'aab- 'to be upright, erect' (as Sasse [1982]), which in 
any case is semantically a much less satisfactory attribution. Gollango evidence in stem-final environment is normally non-determinative of whether to reconstruct PEC ${ }^{*} b$ or ${ }^{*} b$ '.

162. *j'iyann- 'to lie down'

LEC: Afar xiin- 'to sleep, spend the night';

Dullay: Dobase ‘enn- 'liegen'

This root and \#161 preceding appear to contain the same underlying root $*^{*} i(y)$-, each adding a different suffixation (for proposals as to the forms and meanings of such suffixes, see Ehret [1989]).

163. *j'i i - 'to become soft'

LEC: Arbore d'i?- 'to soften';

Yaaku ji'-it-o 'gentle' (stem plus Cushitic adj. suff. in ${ }^{t} t$ )

PEC $*$, rather than $*$, is reconstructed here to account for the Yaaku vowel outcome, /i/ (see $\$ 2$ below).

164. *j'ob- 'drip, drop' (n.)

HEC: Hadiya cop-a 'Tropfen'; cop-iss- 'tropfen, regen' (stem plus Cushitic caus. as denominative);

LEC: Afar xob-exc- 'to spit (of rain)' (exc- 'to say,' used as verb phrase formative in sense 'do'); xob-hee 'to drip' (hee 'put, place')

165. *j'ok'- 'to hit, collide, make contact'

HEC: Burji $d$ 'okk-oom- 'to crunch' (stem plus Cushitic * $m$ intr. extension; $/ k /$ for expected $/ k^{\prime} /$ needs explaining: perhaps geminate $/ k^{\prime} / \rightarrow[k k]$ in Burji at some point in time?);

LEC: Afar xag- 'to touch'; Soomaali dhaq-ay-so 'to strike, hit something on the mark';

Yaaku -jaq-s- 'to throb, beat' (as of heart) (stem plus EC caus.);

Dullay: Harso, Dobase, Gollango soq- 'schlagen'; Saamakko joq- 'to strike'

Soomaali dhag 'colpa, percossa, schiaffo, pacca' shows the sound correspondences found in Afar and can therefore be counted as one among the large number of Northern Soomaali word borrowings from an extinct Afar-related language. Sidamo soq- 'to pound, crush' cannot directly be derived from * ${ }^{\prime}$ 'ok'-, since its regular reflex would be *shoq-; nor can it properly derive from PEC * $s u k$ '- 'to be knocked apart, pounded up' (\#39), which would have suq- as its normal outcome in Sidamo. But its shape and meaning can plausibly be attributed to the confusing of the two roots, the stem vowel coming from * $j^{\prime} o k^{\prime}$ - and the initial consonant coming from * $* u k^{\prime}$-. 
166. *j'ok'- 'to wet'

LEC: Afar xuguug-ul 'obtaining water every day' (partially reduplicated stem by *CVC- > CVCVVC- pattern, plus Cushitic adj. suff. in * $l$;) Soomaali dhaqaaq 'liquifarsi, sciogliersi' (CVCVVC- reduplication pattern; see also examples in $\# 90$, \#137, and \#201 and the Afar instance here); dhaqdhaq 'to swill out' (reduplicated stem);

Dullay: Dobase soq-on-ko 'diarrhoea' (see Saamakko entry); Saamakko joq-om- 'to have diarrhoea' (stem plus Cushitic * $m$ intr. extension); joq-on-ko 'diarrhoea' (verb stem plus gender suff.)

The second Soomaali reflex probably conflates this root with PEC * $t^{\prime} a k^{\prime}-{ }^{*} t^{\prime} i k^{\prime}-$ 'to wash' and the resemblant but probably distinct root seen in Yaaku - $t$ 's $q$ - 'to wet', both of which would also yield the shape *d'aq- (dhaq) by regular Soomaali sound correspondences.

167. *j'ow- 'to be moist';

LEC: Afar xo-yya 'drip, drop' (stem plus Cushitic *y deverb.); Oromo d'ow-a 'valley, gully' (i.e. where stream flows; for same semantics, see Burji entry in \#245 below);

Yaaku joo- $n$ 'faeces' (stem plus Cushitic ${ }^{*} n$ n. suff.);

Dullay: Harso $\$ o o-t-o$ 'Schlamm' (stem plus n. suff. in *t)

Because PEC $* j$ ' became $* d$ ' in Lowland East Cushitic, the root known so far only in its South Lowland reconstruction as *d'uus- 'to fart' [Sasse 1975, 1979] can very plausibly be derived from this root by addition of the causative extension: $*_{j}^{\prime}$ 'ow- plus $*_{-s-}>*^{\prime} j^{\prime} u u s-\left(>\mathrm{LEC} * d^{\prime} u u s-\right.$ ).

168. *j'ub- 'to move quickly about'

HEC: Hadiya cubb- 'to dance'; Sidamo suwu yaa 'to flash by';

LEC: Afar xaxab 'galloping' (partially reduplicated stem); xobox-, xabax- 'to gallop' (2nd form: stem plus EC middle voice extension or metathesized); xabal, dabal 'dance' (xabal-, dabal- 'to wave hands and sway in dance': probably stem plus Cushitic n. suff. in $* l$, with verb as back-formation from noun); Soomaali dhabb-e 'via, strada; sentiero, passaggio; pista'

Afar and Soomaali reflexes require PLEC * $o$. The correspondence of HEC * $u$ to LEC $*_{o}$ in environment of PEC ${ }^{*} b$ and $*^{*}$ ' is an apparently regular outcome: see also \#169 and \#173 below. The PEC vowel reconstruction *u is chosen for this correspondence, reflective of a PLEC phonological innovation, because PEC *o in this environment remained /o/ in HEC: see \#164 above. PLEC short ${ }^{*} o$ then regularly produced $/ a /$ separately in Afar and Soomaali (as also in \#169 following, but not in \#173, where an underlying following geminate shifted ${ }^{*} o$ to long $/ 0 o /)$. 
169. *j'ub- 'to beat (something)'

HEC: Hadiya cup- $a$ 'der Schlägel des Mörsers';

LEC: Soomaali dhabb-ee 'battere l'agave (per farla seccare e ricavarne fibre)'

170. *j'ukk- 'to press with the fingers'

HEC: Hadiya cukk- 'reiben, frottieren';

LEC: Afar $x u k k$ - $u t$ - 'to press firmly, paw all over' (stem plus Cushitic * $t$ continuative extension); xukk-a exc- 'to press hard' (exc- 'to say'; this verb imparts the sense 'be, do' in this usage)

171. *j'umm- 'viscous fluid'

HEC: Sidamo shumm-o 'afterbirth; white of egg';

LEC: Soomaali dhuun 'very sour milk; fluid which emerges from an incised abscess'; Arbore d'uub 'buttermilk'

This root may be a noun formed from root \#167 by addition of the old Cushitic deverbative suffix in ${ }^{*} m$ : $*^{*}{ }^{\prime} o w-m->*^{*} u m m-$.

172. *baj'j'- or *b'aj'j'- 'to clear, open up (especially land)'

HEC: Hadiya bacc- 'einen Wald ausholzen';

LEC: Afar baax- $a$ 'smooth clean place for sitting inside'; baax-o 'country, ground, land'; baax-is-, baar-is- 'to widen' (stem plus EC caus. as denom.);

Dullay: Gollango pas-o 'Feld im Flachland'; Gawwada pas-o 'country'

173. *buj'j'- 'ground'

HEC: Sidamo bussh- $a$ 'soil, clay'; Hadiya bucc- $a$ 'dust, earth';

LEC: Afar boox- $a$ 'plain, flat area, place hollowed out by animal; sandy place where camel can sit and roll': buxux 'bottom end' (for Afar $\mid u /<$ short *ol'j in cases of CVCV(V)C vocalization, as also in \#166 above); Soomaali boodh 'dust'

This root is reconstructed with initial *b rather than the also possible *b' because of its correspondences outside Eastern Cushitic [Ehret 1987:161].

174. *finj'- 'to scatter (intr.)'

HEC: Sidamo fissh- $a$ 'a field in which barley, teff, wheat, etc. are sown'; Hadiya finc- 'sich zerstreuen, auseinandergehen';

LEC: Afar fixix- 'to disperse in all directions' (partially redupliated stem, or stem plus $\mathrm{EC} * d$ ' middle voice extension); fix-it- 'to disperse' (stem plus Cushitic * $t$ continuative); Soomaali fidh-o 'dust (in the wind)' 
175. *haj'- 'to be still, quiet, unmoving'

HEC: Sidamo hash-u yaa 'to be tired of, cease to';

LEC: Soomaali hadh 'to remain';

Dullay: Dobase hashaš-te 'insgeheim' (reduplicated stem)

176. * $k$ 'aj'- 'to soften, become moist and tender'

HEC: Hadiya qac-o 'soft, tender';

LEC: Afar $a x$ - $u x$ - 'to become wet, become damp' (stem plus Cushitic $* d$ ' middle voice extension); Soomaali qaranqaar-o 'pus and hematoma' (reduplicated stem; from southern Standard Soomaali in which $* d$ ' $\left.>r / V_{-}\right)$;

Dullay: Saamakko qaj- 'to melt'

177. *k'ooj'- 'scrotum' (?)

HEC: Sidamo qosh-a 'prepuce'

LEC: Soomaali qoodh 'stud animal'; qoodh-o 'testicles (including scrotum)'

An apparent regular Sidamo vowel-shortening before verb-stem-final $*^{*}$ ' is present here. The other alternative allowed by the Lowland East Cushitic reflex, a shortening of the geminate consonant, is ruled out by HEC's preservation of such $* j ' j$ in other instances, e.g. \#172 and \#173 above.

178. *laj'j'as- 'to be convincing, tell a convincing tale'

LEC: Soomaali ladhac 'to remain impressed, be convinced';

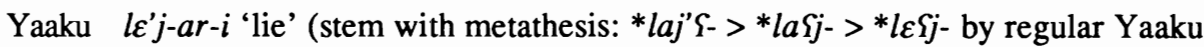
fronting of PEC *a; plus Cushitic n. suff. in ${ }^{*} r$ );

An original gemination of the medial $* j$ is indicated by the preservation of intervocalic $d h$ in southern Standard Soomaali.

179. *maj'- 'to tie up'

HEC: Hadiya macc-o 'breiter Ledergürtel der Männer';

LEC: Afar max- $u y$ 'tying action' (stem plus Cushitic *y inchoative)

180. *maj'-/*mij'- 'to be empty'

LEC: Soomaali madh-an 'empty' (stem plus Cushitic *-an adj. suff.); madh-i 'to empty' (stem plus Cushitic caus. in its regular Soomaali form -i);

Yaaku mij-oni 'deserted homestead'

181. *maj'j'ar- 'to be crazy'

HEC: Hadiya maccar- 'to be crazy'; Sidamo maccarar- 'to be mad, crazy' (partially reduplicated stem);

LEC: Oromo marad'd'- 'to be crazy' (metathesis) 
Sidamo /cc/ here is taken to be the regular Sidamo reflex of PEC $*^{\prime} j^{\prime}$ ' (or of phonemic $/(\zeta \zeta /$ ) in the interconsonantal environment, /\#CV_VC- (see also \#91 for apparently the same rule). For ${ }^{\prime} ' j$ 'j' in the environment /\#CV_V\# in Sidamo, see $\# 173$ and \#188.

\section{2. *miij'- 'to be antagonistic toward'}

HEC: Sidamo mish- 'to despise, scorn, disdain';

LEC: Afar miid- 'to adopt a pose of disagreement, antagonism' (presumed example of not uncommon Afar $x / d$ alternation, e.g. \#151 above, but one in which only the variant with $d$ has been recorded); Arbore miid'- 'to abuse physically or verbally'; Oromo miid'- 'to hurt'

For Sidamo vowel-shortening before $* j$ ' stem-final, see also \#177.

183. *naaj'- 'to exclaim'

HEC: Hadiya naac- 'to jeer';

Dullay: Dobase našs-oo- $d$ '- 'plaudern' (stem plus probably EC ${ }^{*} w$ inchoative plus EC ${ }^{*} d$ ' middle voice extention)

Less plausibly, this item might exemplify the old $\mathrm{EC} * \mathrm{VVC} / * \mathrm{VCC}$ variance, found verb-stem final in some roots (see \#99, \#135, \#137, \#200, and \#207).

One additional root containing word-initial PEC * ${ }^{*}$ ' is noted in the following section (\#209). Because $* j$ ' became $* d$ ' in Lowland East Cushitic, a few of the roots previously reconstructed with $\mathrm{PEC} * d^{\prime}$ ' but not yet attested outside of the Lowland group may actually contain *'j. One probable example, ${ }^{*} j$ 'uus- 'to fart,' has been noted above under root \#167.

1.4. Outcomes of PEC ${ }^{*} x$. A further task of this article is to lay out fuller evidence for the various reflexes of the PEC voiceless velar fricative in the various modern Eastern Cushitic languages. A few of the roots presented here, it will be noted, have been recognized previously by Arvanites [1990] or Sasse [1979]. Among the cognates sets demonstrating ${ }^{*} x$, several additional instances of PEC $*^{\prime},{ }^{*} \xi,{ }^{*} s$, and ${ }^{*} c$ will emerge.

PEC $* x$ had distinctive outcomes diagnostic of each of the three major branches of Eastern Cushitic. Word-initially it produced $/ k /$ in Lowland East Cushitic and $/ h /$ in Highland East Cushitic, while it remained as $/ x /$ in Yaaku and proto-Dullay, two subgroups proposed (independently in Ehret [1976] and Hayward [1978] and again on different grounds in Ehret [1987]) to form a combined Yaaku-Dullay branch. In several present-day Dullay dialects, PD $* x$ has shifted to $/ h /$, but in other dialects it retains its original pronunciation. In non-initial positions non-geminate $\mathrm{PEC} * x$ produced a distinctive outcome only in what have been called the South Lowland East Cushitic languages. That result, $* h$, thus provides a strong phonological testimony for the validity of the South 
Lowland sub-group (Soomaali, Jiiddu, Bayso, etc.; Arbore and Dasenech; and Konsoid and Oromo). Having fallen together with PEC $* h$ in the South Lowland languages, it then followed whatever course of change affected other ${ }^{*} h$ in noninitial environments, yielding a zero outcome, for instance, in most Oromo dialects. In Afar, which Ali [1985] has put in a North Lowland East Cushitic group along with Saho and the extinct Eastern Cushitic languages once spoken in northern Somalia, non-initial PEC ${ }^{*} x$ instead became $/ k /$ as it did word-initially.

The major correspondences can be summarized as follows:

\begin{tabular}{|c|c|c|c|c|c|c|c|c|}
\hline & PEC & Afar & Soomaali & Arbore & Oromo & Sidamo & Dullay & Yaaku \\
\hline /\# & $*_{x}$ & $k$ & $k$ & $k$ & $k$ & $h$ & $*_{x}$ & $x$ \\
\hline $\mathrm{N}_{-}:$ & $* x$ & $k$ & $h$ & $h$ & $\begin{array}{c}h \sim \text { zero } \\
\text { zero } N_{-}\end{array}$ & $h$ & $* x$ & $x$ \\
\hline
\end{tabular}

In the environment \#CV_VC, where the first $\mathrm{C}$ was a labial sonorant, Afar shows $\mathrm{lg} / \mathrm{as}$ its reflex of non-geminated PEC $*_{x}$ (roots \#212 and \#219). Geminate PEC ${ }^{*} x$ apparently fell together with ${ }^{*} k$ in both Highland and Lowland East Cushitic while remaining $* x$ in Dullay and Yaaku.

184. * $x a / * x i$ 'here' (demonstrative stem of location)

185. *xayn-/*xawn- 'when/where'

HEC: Sidamo hann-iyya 'when?, how?'; Hadiya hann-o 'where?'; Derasa haan-o 'when?'; Burji hayn-u 'when?';

LEC: Afar akke 'here, now, at the present time'; ikke 'place' (in subordinate usages);

Yaaku $x a$-' $a$ 'these; those referred to'; $x a$-ani 'places' (simple stem, \#184, plus pl. in ${ }^{*} n$ ); xaut-ete 'now, immediately';

Dullay: Dobase hant- $a$ 'jetzt; bis'; Gawwada Dalpena xant- $u$ 'jetzt'; Gollango hant-a 'jetzt; bis; kürzlich'

Yaaku and Dullay appear to share an innovion, *xawnt- 'now', formed by adding a suffix in $* t$ to the extended stem (\#185) seen in the HEC interrogatives of location in space or time.

186. * $x a b$ - or *xab'- 'to connect, join, attach (tr.)'

HEC: Sidamo hap'-p'-ayy-o 'something that adheres and causes other things to adhere' (stem plus assimilated form of EC $* d$ ' middle voice extension; plus Cushitic *y deverbative);

LEC: Soomaali $k a b$ 'rimettere insiemi i frammenti di qs. con stecchi; riparare qs.; saldare qs.'; Oromo $k a b$ - 'to put together, bind together' 
187. *xac- 'to rub off, scrape away'

HEC: Sidamo hash- 'to wash' (i.e. to scrub off dirt); Burji haas-iy- 'to rub, stroke, massage' (stem plus Cushitic *y inchoative; for Burji lengthening of $* a$ in a parallel environment, $/ \# C_{1-} C_{2}$ - where $C_{1}$ is a voiceless continuant and $C_{2}=r$ or $s$, see \#6 above and \#193 below);

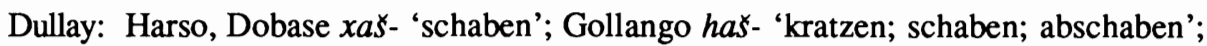
Saamakko xas- 'to hew, carve'

Saho (North LEC) hes-iy- 'to rub' is surely related, but the correspondences for both PEC ${ }^{*} x$ and ${ }^{*} c$ are not those of the language's extremely close relative, Afar. Whether it was borrowed into Saho or not remains, thus, to be determined.

188. *xacc-/*xicc- 'to become dark'

HEC: Sidamo hassh- 'to become dark, night';

LEC: Afar kass-ow- 'to spend the afternoon' (stem plus * $w$ inchoative extension); Arbore kiss- $a$ 'night, darkness'

189. *xaf- 'to hit'

LEC: Afar kaff-at 'a box on the ears' (stem plus Cushitic n. suff. in ${ }^{*} t$ : as singulative?);

Dullay: Harso xaf- 'to hit'

190. *xal- 'grazing grounds'

HEC: Sidamo hal-all-a 'lower, hotter area, where people go occasionally to pasture cattle' (stem partially reduplicated or else plus Cushitic n. suff. in ${ }^{*} l$ );

LEC: Oromo kal-oo 'pasture, leaves and grass, grazing area'

191. *xal- 'joint of body'

HEC: Sidamo hall-o 'side, hip, loins; the middle';

LEC: Soomaali kal 'tibia, perone, omero, e femore; cuore, petto (di sede di sentimenti)'

192. *xaarr- 'hole, gap, space'

LEC: Arbore kaar- $u$ 'gap between top incisors'; Oromo kaarr $-u$ 'space between teeth';

Dullay: Harso xaar-xo 'hole'

Sidamo kaarr-o 'space between the two upper front teeth' has initial $/ k /$ for regular $/ h /$ and must thus be considered a loanword, probably, as in most such cases, from Oromo. The South Lowland attestations show a shared semantic innovation, narrowing the meaning to a particular kind of hole, namely a gap between the teeth (as does the borrowed form of the root found in Sidamo, in 
keeping with the evidence of its having come from the South Lowland language Oromo).

193. *xas- 'to seek, find out'

HEC: Sidamo has-, Hadiya hass- 'to look for, seek'; Burji haas- 'to want';

LEC: Afar kas - 'to remember'; kas 'advice, mind, wisdom'; Soomaali kas 'to understand'

194. *xeyal- 'yesterday'

LEC: Soomaali shalay 'yesterday'; Rendille cele 'yesterday'; Konsoid: Konso xal-a, Gidole hal-a 'yesterday';

Yaaku xaal-in 'yesterday' (stem plus Cushitic n. suff. in *n)

The reconstruction chosen here seeks to account for the vowel length in the Yaaku reflex and for the front vowel $*_{e}$ required for proto-Soomaali by the shapes of the root in the Soomaali group, represented here by Rendille and standard Soomaali. Although the Arbore word heel-i 'yesterday,' because it shows irregular $/ h /$, must have been borrowed from a language (perhaps distantly Yaaku-related) in which $*_{x}$ was preserved, it provides strong support in its attestation of long /ee/ for the the reconstruction of medial *-eya-. Moreover, the Soomaali and Rendille forms can reasonably be interpreted as a pre-protoSoomaali-II metathesis of this root shape: *xeyal- in its SLEC version *keyal-, > PS *kelay > proto-Soomaali-II *celay by the usual Soomaali-II palatalization [Ehret and Ali 1983], thus producing the forms seen today in the Soomaali languages.

195. *xir- 'to come together, join (intr.)'

HEC: Sidamo hir-sis- 'to accompany' (stem plus doubled form of EC caus.);

LEC: Soomaali shir 'reunione; convegno; riunirsi, radunarsi' (regular palatalization here of earlier *kir)

196. *xir- 'to transact'

HEC: Sidamo hir- 'to sell; to buy; to cost';

LEC: Afar kir- 'to hire, rent'

197. *xoob- or *xoob'- 'to surround, enclose by surrounding'

HEC: Sidamo hoow-e, pl. hoobb-a 'enclosure, pen, fold'; hoow- 'to make an enclosure around the houses' Hadiya hoob-ara 'bark of tree' (stem plus n. suff. in $* r$ );

LEC: Soomaali koob-an 'essere circondato; essere cinto' (stem plus Cushitic *m intr. $>n / \_$\# in Soomaali) 
198. *xoobin- 'five'

Yaaku xoop-i 'five';

Dullay: Harso xupin-, Gollango hupin- 'five'; Saamakko xoobin 'five'

The Yaaku $o o$ in place of expected $* 00$ may be due to an underlying contracted shape *xoopn-i, with the stem vowel thus formerly occurring in the necessary environment /_CC for vowel-raising (see §2).

199. *xohr- 'rumbling noise, snoring'

HEC: Burji hoor-is- 'to snore' (stem plus Cushitic caus. as denominative);

LEC: Afar kaar 'snoring' ( ${ }^{*} k o h r->* k a h r->* k a a r-$; original PEC short $* o>$ Afar $\mid a /$ by regular shift); Arbore korah-as- 'to snore' (stem with metathesis plus Cushitic caus. as denominative);

Yaaku -xoor-s- 'to snore' (structure as in Burji)

PEC $*_{o}>$ Yaaku /o/ because of the underlying following $\mathrm{CC}$ environment, $/ *$ C_hr-. For Yaaku vowel outcomes see $\$ 2$ below.

200. *xooleh-/*xolleh- 'goat wether'

LEC: Soomaali: Rendille keleh 'goat wether'; Arbore keleh 'large castrated goat'; Oromo koll-a 'castrated animal';

Yaaku xooleh 'goat wether' (Heine [1975] has kolleh)

This root offers another example of an old Eastern Cushitic -VCC-/-VVCalternance; for other proposed cases see \#99, \#135, \#137, \#183, and \#207. The Omo-Tana reflexes (Rendille and Arbore) show a regressive vowel assimilation. Burji kola 'wether' is a loan, probably from Oromo.

201. *xor- 'to split'

HEC: Hadiya hor- 'to open'; Burji horoor- 'to split' (partially reduplicated stem with *CVC > CVCVVC- vocalization; see also roots \#90, \#137, and \#166 above);

Dullay: Dobase xoxr-o 'hole' (partially reduplicated stem)

202. *xorm- 'male (animal)'

LEC: Soomaali koron 'gelding camel' $\left({ }^{*} m>n /\right.$ /\#); Oromo korm-a 'male animal, bull,' etc.;

Yaaku xoxorm-oori 'penis' (partially reduplicated stem plus n. suff. or number-gender suff. in ${ }^{*} r$;

Dullay: Dobase horon-ko, pl. horm-e 'unkastriertes Haustier'; Saamakko xoron-ko 'male' (of animal) 


\section{3. *xur- 'to leave, move away'}

LEC: Afar kur-o 'ebb, recession'; Oromo kurkur- 'to start to walk (of infant)' (reduplicated stem); kurkur-s- 'to chase here and there' (stem plus Cushitic caus.);

Dullay: Saamakko $x u r$ - 'to leave'

204. *xur- 'to bend, curve'

HEC: Sidamo huru'm- 'to curl up; to curve, arch the body' (stem plus probably allophone of $\mathrm{EC} * d^{\prime},=$ ', middle voice plus Cushitic * $m$ intr. extension)

LEC: Afar kurkurr-e 'knee-cap' (reduplicated stem; semantics: knee as joint used in bending); Soomaali kuraankur 'rotula' (reduplicated stem; possible loan from Afar-related language?); Arbore kur-e 'dance' (see Konso semantics, following); kur-s-at 'knee' (stem plus Cushitic caus. plus Cushitic singulative in ${ }^{*} t$; semantics: thing that one bends, as in Afar, Soomali items); Konso kur-eta 'circular dance' (stem plus Cushitic n. suff. in *t: Oromoid *-ayta)

This entry revises Sasse's [1979] reconstruction of PEC *kir-/*kur- 'circular formation', which relies on Lowland East Cushitic attestations and, along with some acceptable cognates, cites a few unacceptable items, e.g. Soomaali shir 'assembly' (for the source of which see \#195 above).

205. *bax- 'bow'

LEC: Arbore bah 'bow';

Yaaku pax-a 'bow';

Dullay: Harso, Dobase pah-an-ce, Gollango pah-an-te 'bow' (stem + Cushitic n. suff. in $\left.{ }^{*}\right)$;

206. *bex- 'to pour, spill (intr.)

LEC: Soomaali bah 'Pleiades' (semantics: the Pleiades are associated widely along the East African coast with the coming of the first rains);

Dullay: Saamakko bex-ko 'flood'

207. *boox-/*boxx- 'to swell'

HEC: Sidamo bokk-o 'a round shape'; Hadiya bokk- 'to rise (of dough)';

LEC: Soomaali booh-ar 'big or robust person or thing' (stem plus Cushitic n. suff. in ${ }^{*} r$ ); boog 'ulcer' (assimilation *book-ka $<$ *booh-ka, stem plus Soomaali article; see also \#212 below for the same assimilation);

Dullay: Harso, Dobase poox-, Gollango pooh- 'to swell'

For further examples of this kind of alternate root shapes, one with long vowel and the other with long consonant, in early Eastern Cushitic, see \#99, \#135, \#137, $\# 183$, and \#200 above. 
208. *dax-/*daxx- 'to lay across, hence, cover up, conceal'

HEC: Sidamo dah-o 'a hidden place, hiding place'; dah-aaw- 'to be hidden' (stem plus Cushitic $* w$ inchoative as denominative); dah-eess- 'to hide' (stem plus Cushitic caus.); Hadiya dakk- 'sich verbergen';

LEC: Soomaali dah 'coprire qs., nascondere qs.'; dahaar 'involucro, fodero; carapace di tartaruga'; Oromo dakk-u 'loin cloth (old fashioned)';

Dullay: Saamakko daxx- 'to cross'

Oromo $d a$ '- $o$ 'hiding place' is in all probability a Highland East Cushitic loanword because it shows the typically HEC meaning of hiding and a morphology identical to that of the Sidamo noun. The other LEC meanings, in both Oromo and Soomaali, all focus first of all on the action of covering up rather than on its consequence, being hidden.

209. *j'oxx- 'to swell up'

LEC: Afar xokxaak-it- 'to become covered with sores' (reduplicated stem plus Cushitic ${ }^{*} t$ continuative; vowel metathesis of expected *xakxookit-); Soomaali dhak-o 'high point of head; summit, top, apex'; *k $k$ regularly $>k / V_{-} \mathrm{V}$ in Soomaali);

Yaaku -jax-t- 'to swell' (stem plus Cushitic * $t$ continuative extension); jax-at-e 'ulcer'

210. *lax- 'arrow'

HEC: Burji law-ee 'bleeding arrow';

LEC: proto-Soomaali *lahaw 'wooden pointed arrow' [Ali 1985]; Oromo law-aa 'arrow'; Konso law-tta, pl. law-a 'arrow';

Yaaku lax 'arrow';

Dullay: Saamakko lax-e 'arrow'

The Lowland East Cushitic reflexes and the one recorded HEC example of this root share a morphological innovation, the addition of a Cushitic noun suffix in $*_{w}$ to the stem, i.e. ${ }^{*}$ lahw-; hence the shapes attested (these data correct Sasse [1979]). It remains to be determined whether or not the Burji word is borrowed from a Lowland language. Dullay *laax- 'arrow poison', attested in dialects other than Saamakko, has an unexplained long vowel. As it differs in meaning as well, it may be a chance resemblance rather than the same root.

211. *lux- 'to enter'

HEC: Sidamo lukk-i yaa- 'to enter abruptly'; lukk-i ass- 'to stick into', e.g. pocket (ass- 'do');

Yaaku -lox- 'to enter' 
212. *mox?- 'loins'

HEC: Sidamo mo-e 'women's placenta';

LEC: Afar mag-an 'uterus, womb' (stem plus Cushitic n. suff. in $*_{n} n$ ); protoSoomaali *moho? 'waist' (Banaadir-Northern Soomaali mohoog: derivation by assimilation of article as in \#207 above); Oromo mo'-oo 'hip';

Yaaku moxo' 'loins'

213. *mux - 'to cut off'

Yaaku morx-o 'stump' (methathesis of *mox-or-, stem plus Cushitic n. suff. in ${ }^{*} r$; hence failure of expected Yaaku $/ u /<$ PEC * $u /$ _CC-);

Dullay: Saamakko mumuxx- 'to joint, cut up meat' (partially reduplicated stem with gemination of $* x$ )

214. *naxf- 'body'

LEC: Oromo naf-a 'body';

Yaaku naxap 'body (of man or animal)'

For more on this root, see Sasse [1979] and Ehret [1987]. The sound correspondences are not determinative of whether or not Burji naf-a 'body' is a loanword from Oromo.

215. * rax- 'frog'

LEC: Soomaali rah 'frog'; Tunni rakk-e 'frog'; Maay, Garree, Jiiddu rakk-a 'frog'; Rendille rah 'frog'; Oromo raa-cca 'frog'

Tunni, Jiiddu, and other southerly Soomaali languages attest a variant form of the root, ${ }^{*}$ rax $x$-, with geminate final ${ }^{*} x$. This entry corrects previous reconstructions of this root as *rak-.

216. *sax- 'to rub'

LEC: Soomaali sah-o 'affilare qs.; strofinare contra qs.'

Yaaku -sax- 'to wipe, pet'

217. *soox- 'to twist, plait, weave'

LEC: Afar sook- 'to whirl, twist'; Soomaali sooh- 'to weave; to plait'; Arbore sooh'to twist into rope'; Oromo fo'- 'to weave, spin' (Sasse: fooh-); Konsoid: Konso, Gidole sooh- 'to twist, plait';

Dullay: Dobase soox- 'flechten'; Saamakko soox- 'to twist fibers into rope'

This entry corrects the previous reconstruction of this root as *sooh- [Sasse 1975, 1979]. 
218. *siixx- 'to rub'

HEC: Sidamo siikk-is- 'to caress, stroke, pat' (stem plus EC caus.);

Yaaku -siix- 'to rub'

219. *wax- 'to watch'

LEC: Afar wag-it- 'to look at, notice, consider, expect, oversee' (stem plus Cushitic *t continuative); Soomaali wah-an 'preoccupazione; preoccuparsi' (stem plus Cushitic * $m$ intr. extension $>n / \_$in Soomaali);

Yaaku -wax- 'to see'; -wax-sis- 'to show' (stem plus doubled EC caus.)

220. *waxn- 'fence'

HEC: Sidamo onn-a 'thorn fence of cattle pen' (*ohna > onna; meaning given here is inferred by writer from citation of this word in Gasparini [1983]);

Yaaku waxn-o 'fence';

Dullay: Gollango ohin-te 'fence

Konso oxin-ta 'fence' is a loan from Dullay.

221. *zaax- 'to swim'

HEC: Sidamo daah- 'to swim, float on water'; Alaba zak- 'to swim' (< geminated *zaaxx- ?); Burji dah-ad'- 'to swim';

LEC: Soomaali: Jiiddu yoot- 'to swim' $\left({ }^{*} z a a h-w-t\right.$-, stem plus Cushitic ${ }^{*} w$ inchoative, as in Arbore reflex, plus Cushitic ${ }^{*} t$ continuative); Arbore zaw-ahad'- 'to swim' (stem plus *w inchoative plus one of Arbore's forms of EC middle voice extension); Elmolo yow- 'to swim' (stem plus * $w$ inchoative); Oromo daak- 'to swim' (< geminant form *zaaxx-); Gidole taak- 'to swim' (root as in Oromo)

The Oromo and Gidole reflexes attest a shared Oromoid modification of the root, gemination of final ${ }^{*} x\left({ }^{*} z a a x x\right.$-), while Arbore, Elmolo, and Jiiddu shapes share an Omo-Tana innovation, the addition of the Cushitic inchoative extension in $* w$. This entry corrects previous reconstructions of the root, which presumed it to end in PEC ${ }^{*} k$.

222. *?anx- 'where?'

LEC: Afar ank-e 'where?'

Yaaku $\eta k-a$ 'where?'

Dullay: Harso $a h-a, a x-a$, Gollango ah-a 'where?'

For the Yaaku shifts, *VN $>\mathrm{N} / \# \_\mathrm{C}$ and $*^{*}>k / \mathrm{N}_{-}$, see also \#149 above and \#225 below. The Afar phrase anni ikke 'where?', literally 'which place?' (see \#252 below for anni and \#184 above for $i k k e$ ), probably reprises the derivation of this root. 


\section{3. *?axx- 'to look'}

LEC: Soomaali eeg 'to watch, observe, see' $\left({ }^{*} a>e /(\mathrm{N}) g\right.$ in Soomaali, e.g. engeg 'dry' < earlier *angag-, and entry in \#22 above); Oromo akeek- 'to observe, examine, regard' (stem with an uncommon vocalization, ${ }^{*} a \mathrm{CC}>a \mathrm{CeeC}$ ); Konsoid: Konso, Gidole akk- 'to see';

Dullay: Harso ax-icce, pl. axx-e, Dobase ax-acce 'eye'; Gawwada ix-te, pl. ixx-e 'eye'; Saamakko Paxx-ite, pl. ?axx-e 'eye'

224. *?ex- 'to be'; * ?exx- 'to be, become'

HEC: Sidamo $i k k$ - 'to be, become'; Hadiya ih- 'sein'; ik- 'sein, werden'; Burji ih- 'to become';

LEC: Afar $e k k$ - 'to be, become'; Soomaali $a h$ 'essere'; ah-aw 'essere, diventare' (stem plus Cushitic $*_{w}$ inchoative)

225. *?onxod- 'thunder'

LEC: Afar ankad 'thunder' (pl. ankooda: pl. by gemination < *onkodda); unkud- 'to thunder';

Yaaku axanka' 'thunder'

Northern Soomaali onkod 'thunder' is a probable loan from an extinct Afarrelated language since it lacks the usual $*_{o}>a$ shift and is restricted to northern dialects. The Yaaku reflex implies a partially reduplicated root shape * ?axanxat, with normal loss of word-final non-implosive stop.

1.5. Two new PEC nasals ${ }^{*} y$ and $* n$. Finally, it must be proposed, the proto-Eastern Cushitic inventory contained two rare nasal consonants ${ }^{*} \eta$ and $* n$ not previously recognized at all. The evidence, as befits the rarity of the two nasals, is not extensive; and only with the recent publication of several major vocabularies of Eastern Cushitic languages (above all Gasparini [1983], Parker and Hayward [1985], and Agostini et al. [1985]) has enough material become available to make their reconstruction possible. The two consonants are fully preserved in just two Eastern Cushitic languages, Arbore and Yaaku. But they have left a distinct array of correspondences across the rest of the Eastern Cushitic branch:

PEC Afar Soomaali Arbore Oromo Dullay Yaaku Sidamo Burji

\begin{tabular}{|c|c|c|c|c|c|c|c|c|}
\hline$* \eta / \#$ & $g$ & $g$ & $\begin{array}{c}\eta \\
\left(n / /_{+}+\text {front }\right)\end{array}$ & ny & $* n$ & $\eta$ & $g$ & $g$ \\
\hline$*_{\eta} \eta \mathrm{N}_{-}$ & $n g$ & $n$ & $n$ & ny & ${ }^{*} n g$ & ny & $n$ & (?) \\
\hline$*_{n} / \#$ & $n$ & $g$ & $n$ & ny & $*^{*} n$ & ny & $n$ & $n$ \\
\hline$* n / V$ & $n$ & (?) & (?) & ny & $* n g$ & $(n y ?)$ & $n$ & (?) \\
\hline
\end{tabular}


The two consonants collapsed their outcomes in both Soomaali and Oromo, but in different directions. In proto-Soomaali ${ }^{*} n$ and ${ }^{*} \eta$ both produced ${ }^{*} g$ in word-initial position, a result requiring a sequence of two sound shifts: first, $* n$ $>*^{*}$, after which $*_{\eta}>*^{*}$. In non-initial environments, it appears that $*^{*}$, at least, became Soomaali $* n$; and moreover the evidence of Arbore, which also attests $/ n$ / in such environments (see \#239 below and Ehret [1987:\#474]), indicates that this shift is a common innovation of the Omo-Tana branch of Lowland Eastern Cushitic. In proto-Oromo, in contrast, PEC ${ }^{*} \eta$ became ${ }^{*} n$ in both wordinitial and intervocalic environments. Interestingly, $\mathrm{PC} * \eta$ (and presumably ${ }^{*} n$ ) in verb-stem-final position apparently had fallen together with ${ }^{*} n$ in protoLowland Estern Cushitic if not in fact already in proto-Eastern Cushitic itself (see Ehret [1987:\#477]).

The two nasals can provisionally be argued to have fallen together as a single consonant phoneme in proto-Dullay, with $[n]$ and $[n g]$ as its respective wordinitial and intervocalic allophones. In Saamakko, $[n g]$ in word environment /\#CV_VC-appears to have become [ $\eta]$, reconfiguring the phoneme $/ n /$ with an initial allophone $[n]$ and a non-initial allophone $[\eta]$, as proposed by Hayward [1989]. In the non-Saamakko branch of Dullay, proto-Dullay intervocalic *[ng], whether from PEC $* \eta$ or from PEC $* n g$, became $/ n k /$ because of the regular devoicing of $* g$ to $/ k /$ in those dialects (\#239 and \#240; but cf. problematic \#236 where ${ }^{*} n g^{\prime}$ is indicated). Word-initial ${ }^{*}[n]$ in the non-Saamakko versions of Dullay, it seems, was absorbed into $/ n$ / (as indicated in \#230 and \#242).

The Highland East Cushitic group shows still another set of outcomes for the two nasals. PEC $* \eta$ became HEC $* g$ word-initially and ${ }^{*} n$ apparently in other environments (see \#237 below and Ehret [1987:\#471, \#625]). In Sidamo and Burji at least, word-initial $* n$ fell together with $/ n /$, but its outcomes in other HEC languages remain to be worked out.

Fifteen PEC roots containing ${ }^{*} \eta$ are identified here:

226. * $\eta a l$ - 'to make sounds expressive of feelings'

HEC: Sidamo gal-at-a 'praise, thanksgiving' (stem plus ${ }^{*} t$ n. suff.); gal-at- 'to thank, praise' (back-formation from noun); Hadiya galat'- 'to thank' (< *galat-d'-, shape seen in Sidamo plus EC * $d$ ' middle voice extension);

LEC: Soomaali gal-aay-uus 'lamentarsi, gridare' (stem plus Cushitic deverbative suff. in *y plus *-uus- allophone of caus. as denominative; the typically Afar verb morphology here and non-Soomaali shape of the caus. indicate the word is a borrowing from an Afar-related language); Oromo nyal- 'to grumble, grouse'

Burji nyal- 'to be angry' is suggested by Sasse [1982] to be a loanword from Oromo, but the difference in meaning seems too marked for this to be fully satisfactory. A plausible alternative explanation is that the Burji form was adopted from an as yet unrecorded Dullay source that did have the meaning and shape seen in Burji. Another Burji word, gojal-t-iy- 'to groan, moan', would qualify as a proper cognate if, however, its medial sequence -oj-could be 
satisfactorily accounted for-for example, if the form could be derived by regular sound shifts from an underlying *gagal-t-iy-. But for now it remains unexplained. The Highland Eastern Cushitic form of the root appears also as a loanword in Oromo galata 'thanks, praise' (and in Oromo derivatives of that word) and in Amharic.

\section{7. * yals-/*yils- 'to stab'}

LEC: Afar gile 'knife, dagger'; Soomaali galac 'tipo di lancia'; Arbore nele - 'to copulate (of a man)';

Yaaku - -jele's- 'to cut into (meat)' (stem plus Cushitic caus.)

Arbore has $/ e /$ for $\mathrm{PEC} * a$ as a regular fronting shift in the environmont of a pharyngeal. The Yaaku reflex apparently reflects underlying *yalass-, in which two vowel-raising environments both operated, the usual Yaaku pharyngeal rule shifting ${ }^{*} a>{ }^{*} \varepsilon$ and the resulting ${ }^{*} \varepsilon$ then raising to $e$ /_CC (see \$2 below on Yaaku vowels). The Afar form reflects a metathesized root shape *gisl-; for PEC *CVY(V)1-/*CV?(V)1- > Afar CVl-, see also root \#248 below.

228. * yar- 'manhood'

LEC: Arbore yar 'ceremony at which age-set ends' (i.e. when young men graduate into full manhood);

Yaaku garyar-in, pl. garyar 'testicle' (reduplicated stem)

229. *yaar - 'forehead'

HEC: Sidamo gaar-a 'eyelashes; forehead'; Burji gaar- $i$ 'eyebrow';

LEC: Oromo nyaar-a 'eyebrow'; nyaar-oo 'marrow' (semantics: from root in its prePEC sense 'brain': see Ehret [1987]);

Dullay: Saamakko nyaar-a 'forehead'

This entry revises previous proposals about this root, e.g. Sasse [1982:73]. Deriving from PC *yaar- 'brain' [Ehret 1987], the root also appears as protoAgaw *yar-. That 'brain' was its pre-Eastern Cushitic meaning is supported as well by the second Oromo reflex. Oromo gaara 'brow' is a borrowing from $\mathrm{HEC}$, one among a large number of such loanwords known in the language. If the Oromoid root *gaar- 'edge', seen also in Konso kaara 'edge', is in fact a metaphorical usage of this loanword and not a distinct root, then the borrowing of it from HEC would date back to proto-Oromoid times. Arbore naara 'forehead', showing $/ \mathrm{n} /$ for expected $/ \mathrm{\eta} /$, must be accounted a loanword in that language, probably from Dullay.

230. *yaSw- 'crocodile'

LEC: Soomaali gaanni 'croccodrillo maschio adulto' [stem plus Cushitic n. suff. in ${ }^{*} n$ : PEC *CVYC-/CV?C- $>{ }^{*}$ CVVC, ${ }^{*}$ CVIVCC- $/ *$ CV PVCC- $>* C V V C C-$ in 
Soomaali; a variant of the latter shift, *CaSawC- $/ *$ CaPayC- $>*$ CaaCC-, appears here and also in root \#248-specifically *ga ${ }^{*} a w n i>*^{*}$ gaanni and *gaPayl $(i)>*_{\text {gaal }}(l i)$ ]; Arbore yaw? 'crocodile' (metathesized stem with intervening labial $* w$ blocking usual Arbore fronting of * $a$ /pharyngeal); Oromo nyaa-ca, naa-ca, naa-cca 'crocodile';

Dullay: Gawwada Dalpena naSa-acco 'crocodile' (/aa/ in naSaacco implies a lost medial consonant, here indicated to be ${ }^{*} w$; its outcome otherwise would be *na؟-acco)

Burji naacci and nyaanci are loanwords, probably from Dullay dialects and/or from Oromo. Sidamo naacca 'crocodile' is an apparent borrowing from Oromo.

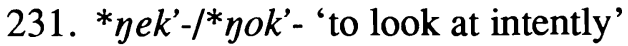

HEC: Sidamo geq- 'to stare threateningly, stare fixedly, give an intense look';

LEC: Soomaali jeeq-aaq 'to wait for; to hope for' (<*geqqaaq-, stem with CVCaaC reduplication as in \#10, \#15, and \#119; gemination of newly medial $* q$ would explain lengthening of ${ }^{*} e ;{ }^{*} g>$ Som. $j$ /_[+front]); Oromo nyonq-ur-s- 'to

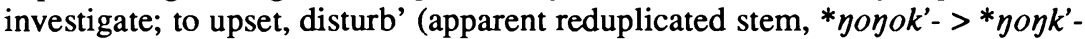
with addition of $* r$ n. suff., plus $*_{s}$ caus. as denominative)

232. * il- 'to grow large'

HEC: Sidamo gill-a 'the natural excrescence that grows up on somebody's face under the ear';

LEC: Afar gil-i 'big toe, thumb'; Soomaali jil 'size, build' (regular Soomaali-II palatalization, $j i l<*$ * gil-); Arbore nil- $i$ 'huge, gross'

233. * oc' $c$ '- 'non-bearing male animal (small livestock?)'

HEC: Sidamo goc'-o, pl. goc'c'-a 'lamb, kid, male of sheep and goats';

LEC: Arbore nooc' 'barren domestic animal, sexually impotent man'

Degemination of ${ }^{*} c^{\prime} c^{\prime}$ in the Sidamo singular can be explained as a backformation from the plural shape, in which $/ c^{\prime} c^{\prime} /$ was interpreted as the common North Highland East Cushitic plural by gemination of stem-final consonant.

234. * orb- 'non-bearing male animal (of cattle?)'

LEC: Soomaali: Jiiddu gurb-a 'male camel';

Yaaku ᄁorp- $a$ 'ox'

Tunni and Maay gurba and Garree kurba 'male (pack) camel' must be accounted as loanwords from early Jiiddu because they show the usual Jiiddu reflex $/ u /$ of $\mathrm{PEC} * o$ instead of their own expected $/ o /$. The southern Oromo term gurb-oo 'young male (pack) camel' reflects a further loanword spread of this usage inland to Oromo speakers. Afar gurbaq-to ([gurbaS-to])'weaned boy' and Northern ('standard') Soomaali qurbac 'young male camel', despite their partial resemblance to the Jiiddu reflex of *yorb-, must be ascribed to a quite distinct root ${ }^{*} k^{\prime} u r b a \varsigma-$, sharply differing in both its reconstructible initial consonant and 
its possession of an additional final consonant not at all present in the * yorb- root. Beyond that, it also fails to show regular sound correspondence in its first stem vowel.

\section{5. *yorm- 'young man, adolescent male'}

HEC: Sidamo goron-s- $a$ 'young man' ( $-s$ - needs explaining: proposed history: stem plus $*_{s}$ caus. as denominative $\rightarrow$ 'to become a young man,' with noun rederived from that verb);

LEC: Soomaali garoom-ey 'pubere (di ragazza)' (stem plus Cushitic n. suff. in *y);

Yaaku yoromin, pl. yoron 'young man'

This root and \#234 preceding can be derived from a common underlying root *yor-/yer-, meaning perhaps 'to mature (of males)', with the form here adding the Cushitic ${ }^{*} m$ deverbative noun suffix and the root of \#234 adding the old Afroasiatic animate deverbative in *b. The proto-Cushitic root *yerd'- 'young man' (Ehret [1987:110] gives 'male human' as its meaning), seen in Arbore nerd'e 'young man, youth', is another derivative of that root (but with the alternate mid vowel realization, as * ${ }^{*}$ er-), plus the old Cushitic middle voice extension in $* d$, implying that an earlier verbal sense of the extended root, 'to exist as a mature male', underlies the PC noun. Root \#228 would certainly appear to have the same underlying source, although its vowel $* a$ is not satisfactorily accounted for by this attribution.

$$
\begin{aligned}
& \text { 236. *caay- 'pot' } \\
& \text { Yaaku saany-a 'waterpot'; }
\end{aligned}
$$

This root also is attested in the PSC root *tsaay-, like the Yaaku form probably originally denoting a waterpot.

\section{7. *k'ooy- 'rind, hull, hard skin'}

HEC: Sidamo qoon-co, pl. qoonn-a 'pumpkin, gourd, skull';

LEC: Afar onk-oor-i 'hull/skin (of grain, fruit)' (stem plus Cushitic n. suff. in *r) Soomaali qoon 'folk, people' (semantics: 'rind' > 'skin' > 'body' > 'person'); Oromo qonyonyny-aa 'scab' (partially reduplicated stem)

The reconstruction here of $* \eta$ rather than $* n$ is required by the wider Afroasiatic comparative evidence [Ehret, in press]. For other cases of a recurrent, sporadic Afar / nk/ alternance with expected / $n g /$, see also \#22 above and \#240 below. The relationship of Burji k'oom-e 'pumpkin, gourd' to this root is unclear; does noninitial $*_{\eta}>$ Burji $/ m /$ in some cases, possibly $* \eta>m /[+$ round $] \_$? 
238. *sin-/*suy- 'nose'

LEC: Gidole, Bussa sin- $a$ 'nose'; Oromo funyny-aan 'nose' (stem plus Cushitic n. suff. in ${ }^{*} n$; gemination as consequence of suffixation)

Three distinct but closely resemblant roots are manifested in the various Eastern Cushitic words for 'nose.' Their resemblance has confused their actual histories in Eastern Cushitic languages, and it has confused the scholarly interpretation of the evidence as well. PEC *sin-/ ${ }^{*}$ suy - given here can be directly derived from the proto-Cushitic root, *isinw- 'nose', seen also in Agaw *isin- and protoSouthern Cushitic *?idigwa. The shape *soon-, seen only in the Eastern OmoTana (Arbore, Dasenech) and Konso words for 'nose' cannot be made to show regular vowel correspondence to it and can be attributed to a separate Afroasiatic root; a third, widely occurring root, PEC *san- 'nose; tip' can similarly can be traced to a distinctive proto-Afroasiatic source (Ehret [in press], for both these attributions).

239. *zay-/*zig- 'to light up'

LEC: Soomaali dan-ab 'flash of lightning' (stem plus Afroasiatic * $p^{\prime}$ ' finitive fortative extension: see Ehret [1989]; PEC * $b^{\prime}$ > Soomaali $b$ ); Arbore zann-e 'charcoal';

Dullay: Saamakko zin-atte 'day' (/ng/ $>[\eta] / \mathrm{V}_{-} \mathrm{VCV}$ in Saamakko) Gollango sink-at-o 'morning'; Gawwada sink-an-o 'morning'

240. *Yay - 'inside of mouth next to cheek'

LEC: Afar qang-axx- $a$ 'mouthful of food' (stem plus EC middle voice extension); qang-ar, qank-ar 'roof of mouth' (stem plus Cushitic n. suff. in *r; this formation was surely influenced by the shape of the older Cushitic root of this meaning, *hank'(ar)- [Ehret 1987:\#523]; qang-ay-s-it-, qang-axx-ay-s-it- 'to chew cud' (stem plus Cushitic $n$. suff. in $*^{*}$ plus Cushitic caus. plus Cushitic * $t$ continuative; 2 nd form inserts EC middle voice extension); qang-ay-tu 'bolus' (stem plus Cushitic n. suff. in ${ }^{*} y$ plus Cushitic ${ }^{*} t$ singulative); Soomaali San 'inside of mouth next to cheek';

Dullay: Gollango Sank-o 'molar tooth'; Saamakko Sang-o 'molar tooth'

For an additional twelve PEC roots, the consonant ${ }^{*} n$ can be reconstructed. The evidence is relatively strong for this phoneme in stem-initial environments, but its non-initial patterns of occurrence remain uncertain.

241. *nik'-/*nak'- 'to constrict, tighten'

LEC: Soomaali jiqjiq 'narrow; tight, close' (reduplicated stem); Oromo nyaq-ii 'tight, secure'

The reconstruction of PEC * $n$ instead of $*_{\eta} \eta$ here is required by the evidence of the proto-Southern Cushitic cognate ${ }^{*}{ }^{y} a k^{w}{ }^{w}$ - 'to constrict, tighten' (by regular 
PSC contraction of underlying partially reduplicated *nanak ${ }^{w '}-$; Ehret [1980:184] incorrectly renders the root as ${ }^{*} n a n k^{w '}$-).

242. *nar-/*nir- 'to be weak, frail'

LEC: Afar nar-iss-o 'term of address for first-born child which is a girl' (stem plus possibly suffixation as for Sidamo entry in \#235 above); Soomaali jirr-o 'ammalarsi' (from earlier *girr- by regular Soomaali-II palatalization shift); jirran 'essere ammalarsi' (stem plus Cushitic ${ }^{*} m$ intr. extension = usually passive/essive in EC); Arbore nar-d'-os- 'to make thin, emaciate (tr.)' (stem plus EC middle voice extension plus Cushitic caus.);

Dullay: Harso, Dobase nar- 'to collapse (house, tree, etc.)'

243. *nark'-/*nirk'-/*nurk'- 'weak, young'

LEC: Afar narg-o 'very young she-camel'; narig 'very young bull-camel'; Arbore $n^{y}$ urk'-i 'weak' (adj.); Oromo nyarq-o 'cammellino'

Soomaali nirig 'camel foal' is a loan from an Afar-related language and has been cogently argued to reflect a spread of the knowledge and practice of keeping camels southward through the eastern Horn of Africa during the first millennium A.D. (see Ali [1985] for the evidence and arguments for this history). The Oromo reflex and the Rendille form of the root, nyirakh 'Kamelfohlen'-the latter a borrowing because of its manifestation of $[n y]$ instead of expected $/ j /-$ have a geographical distribution reflecting an apparently parallel, and presumably contemporaneous, north-to-south line of spread of camel-raising just to the west of the main Soomaali-speaking regions, namely along the eastern fringe of the Ethiopian highlands.

\section{4. *nawr- 'to approach, come up to'}

HEC: Sidamo noori yaa 'to greet' (used to greet person coming from another place);

LEC: Soomaali dul gowr-iir 'incombere su qn. o qs., stare addosso o a ridosso di qn. o qs.; protendersi verso qn. o qs.' (dul 'back, top'; stem plus probably Cushitic $\mathrm{n}$. suff. in * $r$, with v. < earlier n.); Arbore Pil noor- 'to arrive' (Ril 'in'); noor-is- 'to cause to arrive' (stem plus caus.)

245. *nawr- 'to be wet, moist'

HEC: Burji naar- $a$ 'valley' (semantics: 'stream' > 'valley', i.e. the place where a stream flows; for the same semantics in Oromo, see also \#167 above);

LEC: Soomaali gowr-e 'brezza serale molto fresca'; Arbore noor 'mud'

In two other words, gorra?- 'to slaughter' and d'oor- 'to forbid', Burji shows a back rounded outcome for PC *aw / $r$. The first of these is most probably a loanword from Oromo, as Sasse [1982] proposes; the second may be a loanword, too, or else it evinces an alternative outcome dictated by the differing morphological environment of stem-final ${ }^{*} r$. 


\section{6. *naylm- 'quarrel'}

HEC: Sidamo nann-ass- 'to be very angry' (stem plus EC *s caus. as denominative);

LEC: Soomaali geyllan 'combattimento; disputa; combattere; disputare'

The Sidamo assimilation of medial * $\operatorname{lm}$ to $n n$ is also attested in $\# 247$ following.

247. *nayllam- 'very long thing, especially hair, that hangs down'

HEC: Sidamo naann- 'to make a long hairdo on the back of the head'; naann-o 'women's hairdo that falls on the back'

LEC: Soomaali geylaan 'peli molto lunghi; persona alta o cosa lunga che cade rovinosamente'

The noun usage of this root must been seen as primary here, and the Sidamo verb thus derived as a back-formation from the noun. For the same Sidamo assimilation in the non-initial sequence $* I m$, see \#246 preceding.

248. *na?ayl- 'slight, light, thin, meager'

LEC: Afar nal-i 'baby, child, infant; egg'; naal-o 'eggs' (< earlier *nall-, pl. by gemination); Soomaali gaal 'di scarso valore, scadente (di persona o cosa)'; gaall-i 'diminuire, sminuire, ridurre, svalutare qs.' [stem plus Soomaali reflex of Cushitic caus. as a denominative; see PEC root \#230 for the regular sound shift ${ }^{*} \mathrm{CVN} y \mathrm{C}(\mathrm{V})>\mathrm{CVVC}(\mathrm{CV})$, present in these two entries);

Yaaku nya'ayn 'thin' (word-final PEC $* l$ normally $>$ Yaaku $/ n /$, e.g. as in root \#37 above); pl. nya'ayni 'thin; small (suppl. pl.)'

Widespread standard Soomaali nayl 'lamb' is explicable as a loan from an extinct Afar-related language (one of many such items in the northern Soomaali dialects) in which the earlier diphthong did not simplify to $/ a /$ as it did in Afar. Some far northwestern Soomaali dialects have also adopted the naalo form for 'egg', presumably recently from Afar itself. The use of gaal in Soomaali for 'nonbeliever' and 'ruthless, cruel' can be taken as reflecting the conflating of this root with a distinct root denoting people not belonging to one's culture and belief system, found elsewhere among the languages of the Horn.

249. *nih-/*nuh-/*nah- 'to shape a point'

HEC: Burji naa-t-a 'kind of knife' (stem plus ${ }^{*} t$ n. suff.; ${ }^{*} h{ }^{*} h>\varnothing / C V \_C$ in Burji);

LEC: Soomaali gux-uun 'to blunt, clip, bevel (something sharp); blunted, beveled'

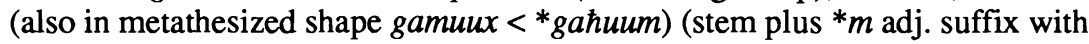
verb < earlier adj.; *m> Soomaali $\left.n / \_\#\right)$;

Yaaku nyih-oi, pl. nyih-o' 'incisor tooth'

Palatalization shifts are of restricted occurrence in Yaaku, most often in wordfinal syllables before ${ }^{*} i$. The evidence available, e.g. Yaaku $n i$ 'in 'small' (containing $\mathrm{PEC} *^{*}$ ) and the Yaaku reflex in $\# 227$ above (containing PEC ${ }^{*} \eta$ ), 
among others, indicates that front-vowel environments do not trigger such shifts for the nasals, certainly not word-initially. Hence, cases of Yaaku ny before front vowels, as here and in \#250 following, should not be attributed to PEC ${ }^{*} n$ or ${ }^{*} \eta$.

250. *nirr-/*narr- 'to break up, break apart (intr.) from being hit'

HEC: Burji naar-ay 'small iron sledge-hammer' (stem plus *y n. suff.);

LEC: Soomaali jiir 'irrompere in qs.' (< earlier * giir - by regular Soomaali palatalization);

Yaaku -nyir- 'to break (from being hit)' (intr.); -nyirs- 'to break (by hitting)' (stem plus Cushitic caus.)

251. * nok'- 'bushy tail'

LEC: Soomaali gooj-i 'to lift the tail' (<*goqqis-, stem plus $*_{s}$ caus. as denominative; regular Soomaali palatalization, $* q>j / i$, and $-i$ reflex of caus.; for a parallel verb derivation overtly attested in Soomaali, see qanaan 'coda; coda degli equini; parte prossimale della coda' and qanaan-i 'drizzare la coda');

Dullay: Saamakko nyoq-oyl-e 'tail (bushy type)' (stem plus EC n./adj.*-ayl, seen also in root \#248 above)

PEC *n rather than $* \eta$ is reconstructed here because it is indicated in the apparent Southern Cushitic cognate form, Iraqw nyaq-onw 'squirrel'.

252. *-n- interrogative base $\left(*\right.$-an- or $*_{-}^{*}$ na- $)$

HEC: Sidamo -na interrogative particle;

LEC: Afar ann-i 'which?' Oromo eenynyu 'who?' (*ay-n-: PEC *ay- 'what?' plus stem);

Dullay: PD interrogative base $*_{-} n g$ - in Gollango $h u-n k-a / t i-n k-a$, Harso, Dobase $h u-n k-a / c i-n k-a$ 'which (masc./fem.)' (hu- $<{ }^{*} k u$ - masculine marker; ${ }^{*} t i$ feminine marker)

Yaaku nysh 'what?' (probably stem plus EC demonstrative root in $* h$ )

\section{Vowel Correspondences of Yaaku}

One sideline to the presentation of data here on PEC ${ }^{*} s,{ }^{*} \xi,{ }^{*} c,{ }^{*} g,{ }^{*}{ }^{*},{ }^{*} x,{ }^{*} \eta$, and $* n$ is the light these data shed on the history of the PEC vowels in the Yaaku language, a topic not explicitly worked out in previous studies. A seven-vowel system emerged in Yaaku from, it appears, the operation of two vowel-raising shifts. PEC ${ }^{*} u,{ }^{*} o,{ }^{*} i$, and ${ }^{*} e$ in most contexts became respectively Yaaku $/ o /$, $/ O /, \mid e /$, and $/ \varepsilon /$. But,

(1) preceding CC (geminate or adjacent different consonants) and

(2) preceding or following a pharyngeal consonant, 
PEC $* u,{ }^{*} o,{ }^{*} i$, and ${ }^{*} e$ yielded the respective Yaaku outcomes $|u /|, o /, \mid i /$, and $\mid e /$. In several instances an earlier morphophonemic gemination, upon addition of verb or nominal-forming suffixes, can be posited to account for high-vowel outcomes, e.g. \#143, \#147, and \#180. This kind of gemination is clearly attested elsewhere in the Eastern Cushitic language group as a goodly number of examples above show-note, among others, the Afar entries in \#97, \#112, \#141, and \#170; the Soomaali cases in \#56, \#66, \#168, and \#169; the Oromo items in \#45, \#46, and \#104; the Sidamo forms in \#67, \#83, \#97, and \#211; the Hadiya reflexes in \#42, \#161, and \#179; the Burji verb in \#165; the Yaaku words in \#143 and \#180; and the Dullay cases in \#66 and \#161 and probably \#183. Subsequently, the geminates degeminated in Yaaku, and the pharyngals $* \Upsilon$ and $* \hbar$ fell together respectively with $* ?$ and $* h$. Realization of PEC $* i$ as Yaaku /i/ may have taken place also in the limited environment /\#C_s(V)\# (\#17, \#104 and the Yaaku reflex isi of PEC * ?is 'she').

In addition, PEC * $a$ fronted to $/ \varepsilon /$ in Yaaku in the environment of a former pharyngeal consonant. The fact that the pharyngal factor affected all five vowels suggests that it might be better to consider the shift of $* a>\mid \varepsilon /$ as simply another facies of the more general rule of vowel-raising in a pharyngeal environment. The limited fronting only of $* a$ in such contexts, which took place in several of the Lowland East Cushitic languages of southern Ethiopia and southern Somalia, would in that case appear a distinct and differently conceived kind of shift.

Finally, it appears that in the restricted environment, /C_ [+velar] where $\mathrm{C}=$ glottal or /j/, Yaaku shifted PEC *o to /a/ (\#165, \#209, and \#225).

\section{Outcomes of Geminated Consonants in PEC}

Two other peripheral issues that these data help to illuminate are the treatments in various languages of the geminates and of consonant clusters of non-laryngeal plus laryngeal stop in proto-Eastern Cushitic roots.

In the Highland East Cushitic languages Sidamo and Hadiya, as well as in the Lowland language Oromo, geminated consonants are normally retained, whereas in the Soomaali group and in Afar the common pattern is for the sequence *VCC to become *VVC. Numerous examples of this latter effect appear all through the evidence offered above. Only intervocalic ${ }^{*} d^{\prime} d^{\prime}, *_{z z},{ }^{*} t t$, and ${ }^{*} k k$ seem generally preserved in Soomaali languages-with ${ }^{*} d^{\prime} d$ ' simplifying to $d h$ and ${ }^{*} k k$ and ${ }^{*} t t$ to $k$ and $t$ respectively in the dialects of standard Soomaali, but often remaining geminate in the other members of the group, and with $*_{z z}$ maintaining geminate reflexes in all of them (examples include roots \#13, \#14, \#145, \#178, \#209, and \#215). In Afar, in contrast, it seems that only ss stays geminated (cf. \#95 and $\# 188$ versus \#13 in which PEC $* z z>$ single /d/). Another effect seen in Soomaali is the lengthening of the following instead of preceding vowel in the PEC shape ${ }^{*} \mathrm{CV}(\mathrm{V}) \mathrm{CCVC}$-, yielding CV(V)CVVC, e.g. \#48, \#82, \#87, \#98, \#150, and \#247. In some Soomaali languages the second outcome was later modified by a 
shortening of the second vowel, e.g. \#24 and \#82. Gemination, though still common in Soomaali and Afar, is usually a morphophonemic effect of affixation in those languages (see above) or comes from recent sound shifts, e.g. PEC *NC $>$ Jiiddu CC).

In $\mathrm{HEC}$, a verb-final gemination of PEC simple $\mathrm{C}$ is itself a freqentative marker (cf. \#1, \#39, \#73, \#111, \#128, \#168, and \#170 among others). This same process can be suggested to appear less often among LEC languages and in Dullay, e.g. the Oromoid reflexes in \#221 and the Saamakko case in \#112, and to have been productive in PEC itself (note roots \#68 and \#218, which seem especially semantically overt cases).

In Yaaku, doubled consonants entirely disappeared, but not without previously affecting the vowel pronunciations of the language (as discussed above); while in the Dullay group a variety of different effects can be discerned in different dialects and in different word environments. These need further study, although a tendency toward shortening of both the consonants and the vowels involved can be discerned in some of the dialects (see \#9, \#84, \#89, \#118, and \#172 for examples of variant outcomes). The situation in Arbore of Lowland East Cushitic is not strongly established from the evidence here, although one pattern does seem incipiently discernible: The one case of PEC *VVCC kept its gemination but shortened its vowel (\#12), while examples of PEC *VCC produced VVC (\#15, \#171, and \#233).

As for sequences of laryngeal and non-laryngeal consonants, only Yaaku seems almost without fail to maintain the PEC distinctions, although of course it did lose the feature [+pharyngeal] and thus collapsed the pharyngeals $* \uparrow$ and $* \hbar$ with $/ P /$ and $/ h /$ respectively. In one limited environment, \#CV_aC-, Yaaku changed PEC * to $/ y /$ if the preceding vowel was $* u$, and to $/ w /$ if it was $*_{o}$ (see \#25 and \#37 for examples; other instances not cited here are also known). In Soomaali, the PEC sequences *VRC, *VYC, *VC?, and *VC all became *VVC, suggesting that the real order of shift was, first, the conversion of these sequences to geminates *VCC, after which the degemination rule just described, *VCC > *VVC, came into play. (See roots \#18, \#31, \#41, \#47, \#50, \#54, \#63, \#84, \#85, $\# 91$, \#95, \#121, \#131, \#159, \#171, \#173, \#207, \#223, \#238, and \#247 for exemplification of the parallel outcomes in the Soomaali group of both the laryngeal sequences and the geminates.) In Afar, in contrast, most sequences *VPC produced VVC, e.g. \#54 and \#160_*VPl and *VS1 yielded V $l$, however (\#227 and \#248)-whereas *VC? and *VCS became instead geminated to VCC, e.g. \#49. Oromo also has contrary outcomes, with PEC *VC? and *VCS producing a non-geminate *VC' (*Vb? and *VbS becoming, for instance, $\mathrm{V} p$ ' as in \#32, \#49, and \#50) or remaining as a sequence, e.g. \#160, but with PEC *VYC and $*$ VPC yielding a geminate VC'C' (\#54) or VCC (\#28). In Sidamo and Hadiya the latter two PEC clusters gave VVC, as in Soomaali, for some kinds of C, but not for others (cf. \#32 and \#37 versus \#16 and \#47 where $C$ was a nasal). But PEC *VC? and *VCS behaved as in Afar, producing VCC (see \#28 and \#49). In 
Dullay dialects and in Arbore of the Lowland branch, it appears that medial ${ }^{*} S$ and $* ?$ were generally lost in $/ \mathrm{CV}_{-}(\mathrm{V}) \mathrm{C}$ contexts, but the range of outcomes remains to be explored, e.g. examples in \#25, \#32, and \#51.

\section{A Revised Array of Proto-Eastern Cushitic Consonants}

With the consonants $* \xi,{ }^{*} c,{ }^{*} g^{\prime}, *^{*}$, and $*^{*}$ soundly, and $*^{*}$ and ${ }^{*} n$ provisionally, established, a much more balanced system of proto-Eastern Cushitic consonants can be presented, with series-filled out in varying degreeof plain voiced stops, voiced implosives, plain voiceless stops, voiceless ejectives, voiceless fricatives, and nasals. Only in the voiced fricative row are fewer than three positions filled as the evidence now stands. Combining the findings of Arvanites [1990] and the materials presented here, the well attested PEC consonants number twenty-eight; and, with the rarer velar and palatal nasals included, they total thirty in all:

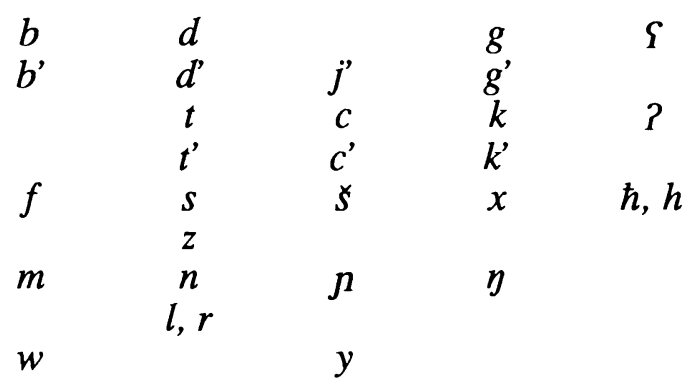

The odd man out among the obstruents, the PEC consonant currently represented as the voiced sibilant $*_{z}$, would contribute to an even neater balance of elements if it could be reinterpreted as originally a non-glottalic voiced palatal stop $*_{j}$. But the wider Cushitic evidence accords best with its having always been $*_{z}$ [Ehret 1987], and so $*_{z}$ in PEC it remains also.

\section{REFERENCES}

Agostini, F., A. Puglielli, and C. M. Siyaad (eds.-in-chief). 1985. Dizionario Somalo-Italiano. Rome: Cooperazione italiana allo suiluppo; Gangemi.

Ali, M. N. 1985. "History in the Horn of Africa." Uiiversity of California at Los Angeles, doctoral dissertation. 
Amborn, H. G., G. Minker, \& H.-J. Sasse. 1980. Das Dullay. Kölner Beiträge zur Afrikanistik, Band 6. Berlin: Dietrich Reimer.

Arvanites, Linda. 1991. "The glottalic phonemes of Proto-Eastern Cushitic." University of California at Los Angeles, doctoral dissertation.

Black, P. 1974. "Lowland East Cushitic: reconstruction and subgrouping." Yale University, doctoral dissertation.

Ehret, C. 1967. Unpublished field collections of Yaaku.

Ehret, C. 1976. "Cushitic Prehistory." In M. L. Bender (ed.), The Non-Semitic Languages of Ethiopia, pp. 85-96. East Lansing: Michigan State University.

Ehret, C. 1980. The Historical Reconstruction of Southern Cushitic Phonology and Vocabulary. Kölner Beiträge zur Afrikanistik, Band 5. Berlin: Dietrich Reimer.

Ehret, C. 1987. "Proto-Cushitic Reconstruction." Sprache und Geschichte in Afrika 8:7-184.

Ehret, C. 1989. "The origin of third consonants in Semitic Roots: an internal reconstruction (applied to Arabic)." Journal of Afroasiatic Languages 2(2):109-202.

Ehret, C. In press. Reconstructing proto-Afroasiatic: Vowels, Tone, Consonants , and Vocabulary. Berkeley: University of California Press.

Ehret, C., \& M. N. Ali. 1984. "Soomaali Classification." In T. Labahn (ed.), Proceedings of the Second International Congress of Somali Studies, vol. 1, pp. 201-269. Hamburg: Buske.

Gasparini, A. 1983. Sidamo-English Dictionary. Bologna: E.M.I.

Hayward, R. J. 1978. "The Qawko dialects and Yaaku." Abbay 9:59-70.

Hayward, R. J. 1982. "Observations of a comparative nature on the S'aamakko language.' Journal of Research on North East Africa. (Only published that one year.)

Hayward, R. J. 1984. "A reconstruction of some root extensions in the Eastern Cushitic verb." In J. Bynon (ed.), Current Progress in Afro-Asiatic Linguistics: Papers of the Third International Hamito-Semitic Congress, pp. 69-109. Amsterdam Studies in the Theory and History of Linguistic Sciences, 28. Amsterdam, Philadelphia: J. Benjamins.

Hayward, R. J. 1989. "Comparative notes on the language of the S'aamakko." Journal of Afroasiatic Languages 2(1):1-53.

Heine, B. 1975. "Notes on the Yaaku language (Kenya)." Afrika und Uebersee 58(2):27-138. 
Keenadiid, Y. C. 1976. Qaamuska Af-Soomaaliya. Muqdisho: Soomaali Academy.

Parker, E. M., and R. J. Hayward. 1985. An Afar-English-French Dictionary. London: SOAS.

Sasse, H.-J. 1975. "Galla / / /, /s/, and /f/." Afrika und Uebersee 58:244-263.

Sasse, H.-J. 1976. "Weiteres zu den ostkuschitischen Sibilanten." Afrika und Uebersee 59:125-142.

Sasse, H.-J. 1979. "The consonant phonemes of proto-East-Cushitic: A first approximation." Afroasiatic Linguistics 7(1):1-67.

Sasse, H.-J. 1982. Etymological Dictionary of Burji. Kuschitische Sprachstudien, Band 1. Hamburg: Buske. 
